\title{
ON SOME MODERN SYSTEMS OF CUTTING METALS.
}

By Mr. W, FORD SMITH, of Maxchester.

In this paper it is proposed to treat of some of the processes of Cutting Metals which the writer has adopted since he read a paper on Tool-holders before the Institution (Proceedings, 1866, p. 288). The success of the round tool-holders then described has led to the further adoption of mechanical means of making and maintaining the tools used in various machines for cutting and finishing metals in their cold state. Such machines are commonly known by the term "machine tools ;" and comprise lathes, planing, shaping, and slotting machines, milling machines, drilling and boring machines, screwing and chasing machines, \&c.

\section{Tool-Holders and Cotters.}

The former paper mainly described what have since become known as right- and left-hand round tool-holders. They are used in different machine tools principally for "roughing out," or, in other words, for rapidly reducing castings, forgings, \&c., from their rough state to nearly their finished forms and dimensions. The tool-holders are called round from their cutters being made of round steel cut from the bar. Notwithstanding that they are very widely applicable, take heavy cuts, and do the bulk of all machine-work in lathes, and in planing, shaping, and slotting machines, it was soon found that they could not compass the whole of the work required in the shops; and it was therefore necessary still to allow the use of some of the common forged tools in conjunction with the round toolholders. This however was objectionable, as no positive rule could then be laid down to define what number of forged tools should be allowed to each workman; and it became apparent that the tool- 
holder system, in order to reach the highest degree of efficiency, must be made complete and independent in itself. This led to the designing of another tool-holder of the most general kind the writer could devise, in the hope thereby to complete the system.

With this object in view, all the remaining forged tools then in use were collected together, and the swivel tool-holder was schemed, Figs. 1 to 3, Plate 19, with cutters so adjustable that they could not only be swivelled round and then fixed to any desired angle, but could also be made to project at pleasure to any required distance in order to reach and cut into all sorts of difficult and awkward corners; in fact to machine any work which the round tool-holder could not finish. Two of the principal objects aimed at were to devise a system of cutters which should not require any forging or smithing, and should yet be capable of being adapted by the simplest possible means, and by grinding the ends only, to all forms which the round cutters would not meet. The special section of steel decided upon was a sort of deep $V$ section, the lower part of which is slightly rounded, as shown in Fig. 4. The angles of the sides give the same amount of clearance ( 1 in 8 ) as that given in the round toolholders, and this same angle of clearance is given to the ground parts. The section of the swivel cutter is made very deep, in order to obtain ample strength in the direction of the pressure it has to support when cutting, as shown by the arrows, Figs. 1 and 4 . The angle of the cutter, as in Fig. 21, Plate 21, is $68^{\circ}$, and is common to every swivel tool-holder. In the cutter for the round tool-holder two angles had been fixed upon as standards, one to cut all kinds of wrought metals, the other all cast metals. To avoid complication however, in the swivel toolholders one cutting angle was fixed upon for all metals, and applied to all cutters. The angle selected, or $68^{\circ}$, is one differing slightly from that of the round cutters, but. is that which worked out the best in practice. The cutters of the round tool-holders are found very advantageous in producing and finishing standard-size round corners in journals of shafts, \&c., and in other cases, where the engineer of the present day is anxious to preserve all the strength possible in the parts; but there are still cases where square, angular, or undercut surfaces 
must be produced, as illustrated in Figs. 5-11, Plate 19. These are front views showing the tool-holders at work planing or shaping. They are supposed to be travelling forward, or the work to be moving in the opposite direction; and the arrows in each view indicate the direction in which the tool-holder is being fed at each stroke of the machine, to take the next cut.

Fig. 5, Plate 19, shows the mode of planing the under horizontal surface of a lathe bed. The cutter shown in use is ground to an angle of $86^{\circ}$, or $4^{\circ}$ less than a right angle, and thus has a clearance of $2^{\circ}$ at each side when cutting either horizontally or vertically. This cutter is very general in its applicability, and is devised so as to finish with one setting both the vertical surface $A$, and the horizontal surface $H$, without the necessity for disturbing the cutter in any way. The ordinary system is to use at least two tools for roughing out, and two for finishing, on two surfaces at right angles with each other.

Fig. 6, Plate 19, shows the method of planing in a very limited space the under horizontal surface $S$; the corresponding surface $B$ is planed afterwards, without disturbing the tool-holder in the toolbox, by simply slacking the nut, swivelling the bolt $N$ half-way round, replacing the cutter with one of the opposite hand, and again securing it by the nut.

Fig. 7, Plate 19, shows a swivel tool-holder clearing without diffeulty a boss which projects and would be very much in the way of any ordinary tool. The cutter in this case planes not only the horizontal surface $C$, but the inclined surface $V$ also, with one setting and without being disturbed in the tool-box.

Fig. 8, Plate 19, shows the method of eutting a vertical slot in a horizontal surface of metal. The cutter in this case is called a parting tool. Fig. 9, Plate 20, is a side elevation of this same cutter, showing the cutting angle, which is $68^{\circ}$.

Figs. 10 and 1.1, Plate 19, are tool-holders with cutters of rather special forms. The former is shown planing out or under-cutting a $\mathrm{T}$-shaped slot; and the latter is planing out a small rectangular clearance corner.

Figs. 12 and 13, Plate 20, show a swivel tool-holder with a round shank, such as is used on the slide-rest of a screw-cutting lathe, for 
cutting square threads. It is carried on a wrought-iron or steel block, provided with a groove, semicircular in section, in which the round shank of the tool-holder lies, and is clamped down in the usual way. The cutters for cutting out the spaces between the square threads are of very simple form, and by aid of this tool-holder any tool made to the correct width of the space will cut either right-hand or left-hand screws, no matter whether they are single threads, double threads, or any other. To cover the same ground with forged tools, no less than six expensive cutters would be required, each one forged from square steel, and carefully filed up and hardened. With the tool-holder only one cutter is required, and it costs probably not more than 10 per cent. of one of the six forged tools, while it maintains its size much better, and consequently lasts much longer. It also takes off about twice the weight of cuttings per hour as compared with an ordinary forged tool. This system is useful where many screws of odd forms and pitches are required; but where there are sufficient numbers to be cut, special chasing lathes are far preferable to ordinary screw-cutting lathes, as they will do about six times as much chasing of $V$ threads, or cutting of square threads, as can be accomplished in the ordinary lathe in the same time. Instead of carrying one chaser, the chasing lathes carry, in a chasing apparatus, three or four chasers; and these have their threads, whether square, $V$, rounded, or any other form, cut in their places by aid of a master tap. They are then tapered at the mouths, backed off, and hardened ready for work. The number of shavings cut simultaneously from a screw by this process varies from twelve to twenty-four, according to the size, strength, and pitch of the thread. Screws up to 6 in. diameter can be very rapidly cut by this system, on which very much more might be said if time permitted. A few screws cut by this process are exhibited.

When the two systems-the round and the swivel tool-holderare worked in conjunction with each other, their universality of application is so thorough that almost every difficulty is met; and it was only in the case of paring and shaping articles in the slotting machine that two modifications had to be made in the holders, the same cutters being still applicable. 
The Capstan-rest Chasing Lathes designed by the writer's firm have now become much used; and as a large amount of their work is produced from black bars of iron, steel, or other metals, each of which has to be finished at its extremities and cut or parted off, it was found advisable to make one special tool-holder, Figs. 14 to 17, Plate 21, for carrying tools of the correct sections to produce the desired shapes for the ends: the tedious and unreliable process of turning the ends with hand-turning tools is thus avoided. Each cutter is of absolutely the same section throughout its entire length, and the re-sharpening is done by grinding the end of the cutter only, so that it can only produce the same standard form as long as it lasts, that is to say till it is ground too short to be used any longer. The parting off might have been accomplished by the swivel tool-holder; but a special form, Figs. 18 to 20 , is found to be more convenient in parting off close up to the chuck or lathe spindle.

To produce a maximum amount of cutting in a minimum space of time, there are two main points which must be carefully attended to. These seem to be applicable to all cutters for cutting metals, whether they happen to be those fixed rigidly in tool-boxes, as in turning-lathes, planers, shapers, slotters, \&c.; or those which cut while they revolve, as milling-cutters, twist-drills, boring-bits, \&c.

These two important points are:-

First, the cutting angle, or angle of the cutting surface, Fig. 21, Plate 21, i.e. that surface which removes the shavings of metal, and upon which the pressure of the cut comes, as shown by the arrow.

Secondly, the clearance angle, or angle of the clearance surface, i.e. that surface which passes over the surface of the metal that has been eut, and does not come in contact with the metal at all.

To produce the best results, and to ensure the utmost simplicity, it is important that these two angles be correctly constructed in the first instance. The best measure for both angles has been arrived at from actual practice and a series of experiments. When once obtained and started with, they should not alter by use, but should always remain constant, if the greatest amount of cutting efficiency is 
to be attained. When aided by a mechanical system of re-grinding, and the use of standard angle-gauges, Figs. 22 and 23, Plate 21, there is no difficulty in maintaining the exact angles. The only changes which take place are that the cutters in tool-holders become gradually shorter by grinding, and that milling cntters during a long period of time become very gradually smaller in diameter, by the process of re-sharpening them on a fine emerywheel. In the case of the tool-holders, as already explained, the cutting angle is maintained by the system of re-grinding, and the tool-holder itself always maintains the clearance angle. The system is thus simplified, as will be clearly understood when it is remembered that each one of the tool-holder cutters, no matter of what description, is ground on its end only. Thus the section is never altered, no smithing or alteration in form is necessitated, and consequently no repairing has to be done in the smith's shops.

The objects aimed at have been :-

1st. To produce the highest class of workmanship, by providing the best known form of cutters, carefully made, and capable of having their cutting edges accurately re-ground, so that the surfaces of the machined work may be produced direct from the cutters so highly finished that no hand-work could possibly improve them. Most of the turning of wrought iron, for instance, may be so perfectly finished that there is no necessity to polish it by means of emery or emery-cloth.

2nd. To make all the cutters so free from complication, and simple to keep in order, that no difficulty or error may occur in re-grinding them.

3rd. Since finely-polished surfaces cannot be obtained without the most perfect cutting edges, to make all cutters not only of the best steel, but with their cutting edges most accurately and carefully ground up, in almost all cases by mechanical means. The durability of the cutters, from their construction and high class of material, is very great, and they are thus capable of removing a great weight of metal in a given time.

The grinding or re-sharpening of all cutting edges is reduced to the greatest simplicity; and only three descriptions of machines 
aro requisite for this purpose. They are all arranged to grind mechanically; that is to say, tho cutters whilo being ground are carried and pressed on the grindstone or emery-wheel by mechanism. The requisite forms and angles are also obtained by mechanism, it being found in practice that sufficient accuracy cannot be secured by hand-grinding.

The machines aro as follows:-

1st. A grindstone with slide-rest, for grinding all the cutters used in tool-holders.

2nd. A twist-drill grinder; this also is by preforence a grindstone, with mechanism for holding and guiding the twist-drills. A machine with an emery-wheel in place of the stone is also used for the grinding of twist-drills, with much the same mechanism for carrying the drills. In practice howevor the stone grinds about double the number of drills per hour, and with less risk of drawing the temper. Both stone and emery-wheel are run at a high speed, and used with water.

3rd. A small but vory complete machine, ono of which is exhibited, for re-grinding milling-cutters. In this case gritstone does not answer, and the grinding wheels are obliged to be of emery or corundum. They are very small in diameter, and many of them are exceedingly thin, and so delicate in form that if mado of gritstone they would rapidly lose their shapes. They are run at a high speed, $3000 \mathrm{ft}$. per min., and are turned into form whilo revolving by means of a diamond.

A milling-cutter will work for a day, and in many cases for two days, before showing signs of distress. Before the cutting edges are visibly blunted, but as soon as the sense of touch indicates that their keenness is diminished,* the cutter should be put into this machine; and the probability is that not more than 1-1000 in. need be ground off each tooth, before it is restored again to a cutting edge almost as fine as that of a wood chisel. Each cutting edge, or in other words cach tooth of the milling-eutter, is only passed rapidly

* The sense of touch, in passing the finger over the cutting edges, conveys the idea of slight bluntness better than it can be detected by the eye. 
once or twice under the revolving wheel, which is itself of very fine emery. It can therefore be readily understood how delicate an operation this is, and why emery alone will answer for it.

In order to maintain the correct forms and angles of all cutters for tool-holders, sheet-steel angle-gauges, Fig. 22, Plate 21, are provided, and the process of grinding is thus reduced to a complete and exceedingly simple system. In well-regulated shops, a young man is selected to work each machine for cutter grinding; and in practice each man so engaged can keep a works employing 150 men (exclusive of moulders or boiler makers) well supplied with all the necessary cutting tools from day to day. A very great saving is thus effected, as no machine need ever stand idle for want of cutters, and no repairing of tools in the smithy is needed.

Take for instance an engineering works employing 250 men. The requisite number of improved grinding machines, with special mechanical appliances, is as follows :-

Two patent grindstones for re-sharpening cutters mechanically.

One patent twist-drill grinder for re-sharpening twist-drills mechanically.

One improved cutter-grinder with small emery-wheel, for re-sharpening the cutters used in milling machines.

To follow the system out satisfactorily, the man working the grindstone goes round to each machine every morning, collects together those cutters which have been blunted by use the previous day, carries them to his grindstone, re-sharpens them, and distributes them out again to each machine;--which is thus kept well stocked with an ample number of cutters, always ready for immediate use.

The cutters for tool-holders do not require any repairing in the smithy; consequently that operation, which is costly in so many ways, is avoided, and jobbing or tool smiths with their strikers are almost entirely dispensed with.

For re-hardening the cutters, a rule is made that when the grinder meets with cutters which are not as hard at their cutting points as they ought to be, he puts them on one side, and periodically, say once every fortnight, he sends the lot into the smithy for the end 
of each to be re-tempered. This is a very inexpensive operation, the time occupied being about two hours per fortnight. They are placed in a small oven by dozens and very, slowly heated up to a dull red; the end of each cutter is then plunged into a perforated iron box immersed in water till the bottom is covered to the required depth for hardening the cutter up to the proper distance from its point. The cutters are left standing in a nearly vertical position in the box of water, until they have gradually cooled down sufficiently to be removed. They are then sent to the grindstone, re-ground, and given out with the other cutters to be used again in the different machines. With steel of the highest quality for cutters, it is most important to keep it out of the smith's fire entirely, if possible. That object is here attained, the cutters never going to the fire except for re-hardening. During the life of a cutter it only sees the fire probably six times.

As the weight of each cutter is small, usually not more than from $\frac{1}{15}$ th to $\frac{1}{20}$ th that of a forged tool used for the same purpose, the outlay for best tool steel is not heary; and the engineer is not tempted to purchase any but that of the highest quality. With such steel, especially when used in the best manner, each machine is capable of cutting at a high speed, and the cuts may be coarser than those ordinarily taken. When the swivel tool-holders were first used on planing machines, cutting slots 1 in. broad into solid castings, it was found that two teeth of the feed could be used at each stroke. Previously a forged tool of the same breadth, ground to form by the planer to the best of his ability, had been used in the same machines; but he found, on trial from time to time, that it was impossible to use more than one tooth of the feed; or, in other words, the tool-holder cut a given depth into the metal in half the time of the forged tool.

Again, when the swivel tool-holders were first used in cutting square-threaded screws, the utmost the lathe could do with ordinary forged tools, ground only by the judgment of each man and not to the best selected and standard angles, was to take four degrees of feed at each cut, as indicated by the micrometer feed-wheel. The tool-holder on the other hand took seven degrees of feed in the 
same lathe, doing the same work, and producing quite as good or a better finish with the same expenditure of steam power.

The cutters for the swivel tool-holders can not only be made at the outset, but also constantly maintained, at the best and most efficient angles which practice can teach; it therefore follows that a very much better class of machine-work can be produced. The finished surfaces obtained from the tool-holders show a striking superiority over those from forged tools, especially when in the latter the angles are ground by hand, by each man or boy working a machine, who of course has not made a study of the best angles. The tendency then is to grind the cutters to all sorts of incorrect forms, which more or less tear the surfaces of the machined work, and leave bad finishes, such as require a considerable amount of hand-labour bestowed upon them afterwards, in filing, scraping, and polishing.

Again, the tool-holders have led up to a considerable extension of what is called Broad-finishing, in planing, turning, shaping, slotting, \&c.

Broad-cutting feeds, varying from $\frac{1}{2}$ in. to $1 \frac{1}{2}$ in. in width, are very commonly taken by the swivel tool-holders, and more accurate surfaces produced than with finer feeds. The advantages in point of time saved are very great; the time occupied in finishing by broad-cutting being from one-twelfth to one-twentieth of that consumed by finishing with ordinary feeds and in the usual manner. Some samples of this kind of finishing lie on the table, together with the cutter which was used.

The width of broad-cutting can be increased to any desired limit, and there have been special cases where it has been advantageous to take thin shavings 3 in. to 6 in. in width.

The principal limits to broad-cutting are as follows :-

1st. The power of grinding the cutting tool to a sufficiently straight or true cutting edge: the best plan of course is to do this. by mechanical means.

2nd. The securing of sufficient stability in the machine tool to hold the broad-cutter so rigidly up to its work that neither the cutter itself nor the work may spring away, and that no jarring or 
injurious vibration may be produced, and impart its evil effect to the finished surface.

3rd. The securing of sufficiently accurate work to answer the purpose for which it may be required. For instance, the piece of work planed or turned by this process may be a portion of a large railway bridge, where absolute accuracy is not requisite; or on the other hand it may be some portion of a machine tool, where the utmost accuracy is needed; or again, some part of an engine, where the builder is anxious to obtain all the accuracy which can possibly be produced direct from the machine tool.

\section{Twist-Drills.}

During the last thirty years many attempts have been made to introduce a better system of drilling and boring; and on this subject very much might be written if time permitted. Many engineers have used square bar-steel, which the blacksmith has twisted, and then flattened at one end to form a drill. The object of the twisted stem was to screw the cuttings out of the hole, and to some extent this succeeded, but not perfectly. The twisted square section revolving in the round hole had a tendency to crush or grind up the cuttings; and if they were once reduced to powder it was difficult (especially in drilling vertically) for the drill to lift the powdered metal out of the hole.

In most cases the lips of these drills were of such form that the cutting angle, or face of each lip, which ought to have been about $60^{\circ}$, Fig. 21, Plate 21, was $90^{\circ}$, or even still more obtuse : this being an angle which would scrape only, but could hardly be expected to cut sweetly or rapidly.

Again, there were attempts to make the cutting angles of the two lips of much the same number of degrees as that given by the twist itself in a good twist drill. This was done by forging or filing a semicircular or curved groove on the lower face $F$ of each lip, Figs. 24 and 25, Plate 22. For a short time lips thus formed cut fairly well; but a very small amount of re-grinding soon put them out of shape, and made them of such obtuse cutting angles that good results could no longer be expected from them ; and to be constantly sending 
such drills to the jobbing or tool smith, and then to the fitter to file into form again before they were re-hardened, was found to be too tedious and too expensive. Again, to arrive at the best results in drilling, each of the cutting lips should make the same angle with a central line taken through the body of the drill; in other words, the angles $\mathrm{A}$ and B, Fig. 26, Plate 22, should each have exactly the same number of degrees, say $60^{\circ}$. The clearance angles also should be identical, and the leading point $P$ should form the exact centre point of the drill. From practice it is found that, if these proportions are not correct, the drill cannot pierce the metal at more than about half the proper speed, and the hole produced will also bo larger than the drill itself. To give an idea of the excessive accuracy which must be imparted to a twist-drill, we must bear in mind that even a good feed is only $\frac{1}{100}$ in. to each revolution; and as two lips are employed to remove this thickness of metal, each lip has only half that quantity to cut, or $\frac{1}{2} \frac{1}{0}$ in. This $\frac{1}{200}$ in. is as much as can be taken in practice by each lip in drills of ordinary sizes. It will therefore be readily understood that if one lip of a drill stands before the other to the extent of $\Sigma_{2 \frac{1}{0}}$ in. ouly, the prominent lip, or portion of a lip, will have to remove the whole thickness of the metal from the hole at each turn. The lip of a drill will not stand such treatment; and it is therefore obvious that if this were attempted the prominent lip would either break or become too rapidly blunted. To get over these difficulties, the driller would no doubt reduce his feed by one-half, or to $\frac{\mathrm{l}}{200}$ in. per turn, which would mean about half the number of holes drilled in a given time.

This nice accuracy, although absolutely requisite, cannot be produced by hand-grinding; neither can a common drill, having a rough black stem more or less eccentric, be ground accurately, even by aid of a grinding machine with mechanism for holding it. To grind any drill accurately, it must be concentric and perfectly true throughout with the shank, as that part has to be held by the drill-grinding machine. If the drilling is to be done in the most rapid manner-in other words, at the smallest cost, -and if the best class of work is also desired, it seems certain that a twist-drill, 
with all the accuracy which can possibly be imparted to it in its manufacture, and with the greatest care employed in the re-sharpening, is the only instrument which can be employed.

About a quarter of a century ago both Sir Joseph Whitworth and the late Mr. Greenwood of Leeds made some twist-drills; but it is to be presumed that a large amount of success was not achieved with them, and for some reason the system was not persevered with. After that period the Manhattan Fire-arms Company in America produced some beautifully-finished twist-drills. Though the workmanship in these was of a superior description, the drills would not endure hardship. It was found that the two lips were too keen in their cutting angles, and that they were too apt to drag themselves into the metal they were cutting, and finally to dig in and jam fast, and twist themselves into fragments. Mr. Morse then took the matter up, and by diminishing by about 50 per cent. the keenness of the cutting lips of twist-drills made a great success of them. He used the grinding line, AB, Fig. 29, Plate 22, and an increasing twist. In such a drill, of the standard length, and before it is worn shorter by grinding, the twist is so rapid towards the lips that the angle they present, or what has been already referred to as the angle of the cutting surface, is very nearly the same as that which the writer had previously established for cutters cutting metals, as in Fig. 21, Plate 21.

If however the angle of twist is made to increase towards the lips, it will of course decrease towards the shank, as in Fig. 29, Plate 22. The shorter the drill is worn, the more obtuse the cutting angle becomes, and the less freedom will it cut with: supposing of course that, when the drill was new, the angle was the most efficient. Suppose this decrease of twist were carried still further by lengthening the drill, a cutting angle of $90^{\circ}$ would eventually be arrived at. The old common style of drill usually has such a cutting edge; which is so obtuse as not to cut the metal sweetly, but on the contrary to have more of a tearing action, and thus to put so much torsional strain on the drill that fracture is certain to take place, even if what the writer would now consider a moderate feed was put on by the drilling machine. 
It is thorefore obviously advantageous to adopt from the first the best cutting angle for all twist-drills, and to preserve this same angle through the whole length of the twisted part, so that, however short the drill may be worn, it always presents the same angle, and that the most efficient which can be obtained. This cutting angle is easy to fix, and becomes an unalterable standard which will give the best attainable results. This has been adopted at the Gresley Works Manchester, and of course applies to both lips.

A common drill may "run," as it is usually termed, and produce a hole which is anything but straight. This means that the point of the drill will run away from the denser parts of the metal it is cutting, and penetrate into the opposite side which is soft and spongy. This is especially the case in castings; where, for instance, a boss may be quite sound on the one side, while the other side, being next to a heavy mass of metal, may be drawn away by the contraction of the mass in cooling, so as to be very soft and porous. In such cases it is perfectly impossible to prevent a common drill from running into the soft side. This sort of imperfect hole is most trying to the fitter or erector; and if it has to be tapped, to receivo a screwed bolt or stud, is most destructive to steel taps. The taps are very liable to be broken, and an immense loss of time may also take place in attempting to tap the hole square with the planed face. A twist-drill, on the other hand, from its construction, is bound to penetrate truly, and to produce holes which are as perfect as it is possible to make them.

The next important step in twist-drills has been to fix a standard shape and angle of clearance for both lips, which should also give the best attainable result. This angle might be tampered with if the re-grinding were done by hand, and too much or too little clearance might easily be imparted to the drill from want of sufficient knowledge on the part of the workman. If too little clearance, Fig. 30, Plate 22, or in some cases none at all, is given to the drill, the cutting lips then cannot reach the metal, consequently they cannot cut. The self-acting feed of the drilling machine keeps crowding on the feed until either the machine or the drill gives way. Usually it will be the latter. 
Again if too much clearance is given, Fig. 31, the keen edges of the lips dig into the metal, and embed themselves there, and of course break off.

Fig. 32, Plate 22, is drawn exaggerated, in order to show the ill effect of grinding one lip of a drill longer than the other. It is found that the centre point $\mathbf{P}$ of the drill will be kept, by the pressure of the feed in the direction shown by the arrow, in the centre of the holo which is being drilled. Then there is a long lip and a short one sweeping round. The hole drilled will therefore be in diameter $i$ wice the radius of the longer lip $R$, or larger by the distance $D$ than the size of the drill itself. This is very undesirable. A much graver defect, arising from this incorrect grinding, is that the drill can only penetrate into the metal it is boring at about half the speed it ought to attain if it were accurately ground. For each lip can only take a certain thickness of shaving per revolution; and if this maximum thickness were taken by the two lips they would remain comparatively uninjured. But the portion $\mathrm{C}$ of the long lip would have a double cut upon it (the other lip not cutting at all at this outer portion of the conical hole): hence it would not stand such usage, and would either rapidly blunt itself or would break.

The grinding line A B, Fig. 29, Plate 22, was introdnced in the United States, to assist the operator in keeping both lips of the drill identically the same. To arrive at this however is more than can be accomplished by hand-grinding, as not less than three points have to be carefully watched, namely :-

1st. That both lips are exactly the same length;

2nd. That both have the same clearance angles;

3rd. That both make the same angle with the centre line on the body of the drill.

If these are not attended to, the drill lips may for instance be both ground so as to converge exactly to the grinding line at the point or centre of the drill, and may still be of such different lengths and angles as to produce very bad results in drilling.

Much ingenuity has been expended on machines for the grinding of the two lips with mechanical accuracy. The one which has been the most successful in the United States has three motions, 
ingeniously combined with each other. So many motions however entail complication; and this, added to a system of holding the drill which was not sufficiently reliable, failed to produce the extreme accuracy it is requisite to impart to the two angles.

The grinding line too is found to be more or less a source of weakness. It is therefore advisable to dispense with it if possible; and where a good twist-drill grinding machine is used, the grinding line is seldom or never looked at, and in that case is useless. If it is still desirable to have grinding lines (as in some cases where hand-grinding has to be relied upon), they should be made as faint as possible, and not cut deeply into the thin central part of the drill, so as to weaken it.

A simple and efficient twist-drill grinding machine was so much needed that within the last three years the writer, aided by his firm, has designed one. The twist-drill in this machine has only one motion imparted to it, to produce the two lips of each drill as perfect facsimiles of each other and with the desired amount of clearance. .Many of these machines are now at work. That the drills ground by them are accurate is proved by the holes drilled being so nearly the size of the twist-drill itself that in many cases the drill will not afterwards drop vertically through the drilled hole by its own gravity; in other words, the hole is no larger than the drill which has drilled it. It is not generally known that this is the most severe test which can be made of the accuracy of re-grinding, and of the uniformity of all parts of the twist drill.

One of the smallest-sized machines is exhibited. The largest machine grinds drills of 3 in. diam.; and there are intermediate sizes.

The whole of the drilling in many establishments is now done entirely by twist-drills. Since their introduction it is found that the self-acting feed can be increased about 90 per cent.; and in some engineering works the feeds in some machines have been increased by fully 200 per cent., and consequently three holes are now being drilled in the same time that one was originally drilled with the old style of drill and with old machines.

It may be interesting to give a few results out of numerous tests and experiments made with twist-drills. 
Many thousands of holes $\frac{1}{2}$ in. diam. and $2 \frac{3}{4}$ in. deep have been drilled, by Smith and Coventry's $\frac{1}{2}$-in. twist-drills, at so high a rate of feed that the spindle of the drilling machine could be seen visibly descending and driving the drill before it. The time occupied from the starting of each hole, in a hammered scrap-iron bar, till the drill pierced through it, varied from 1 minute 20 seconds to $1 \frac{1}{2}$ minute. The holes drilled were perfectly straight. The speed at which the drill was cutting was nearly $20 \mathrm{ft}$. per min. in its periphery, and the feed was 100 revolutions per inch of depth drilled.

The drill was lubricated with soap and water, and went clean through the $2 \frac{3}{4}$ in. without being withdrawn; and after it had drilled each hole it felt quite cool to the hand, its temperature being about $75^{\circ}$. It is found that 120 to 130 such holes can be drilled beforo it is advisable to re-sharpen the twist-drill. This ought to be done immediately the drill exhibits the slightest sign of distress. If carefully examined, after this number of holes has been drilled, the prominent cutting parts of the lips, which have removed the metal, will be found very slightly blunted or rounded, to the extent of about $\frac{1}{100}$ inch; and on this length being carefully ground by the machine off the end of the twist-drill, the lips are brought up to perfectly sharp cutting edges again.

The same sized holes, $\frac{1}{2}$ in. diam. and $2 \frac{3}{4}$ in. deep, have been drilled through the same hammered scrap iron at the extraordinary speed of $2 \frac{3}{4}$ in. deep in one minute and five seconds, the number of revolutions per inch being 75 . An average number of 70 holes can be drilled in this case before the drill requires re-sharpening. The writer considers this test to be rather too severe, and prefers the slower speed.

The drills in both cases were driven by a drilling machine in a true-running spindle, having a round taper hole, which also was perfectly true; the taper shank, and the body or twisted part of the drills, also ran perfectly concentric when placed in the spindle, or in a reducer or socket, having a taper end to fit the spindle. When the drills run without any eccentricity, there is no pressure, and next to no friction, on the sides of the flutes; the whole of the pressure and work being taken on the ends of the drills. 
Consequently they are not found to wear smaller in diameter at the lip end, and with careful usage they retain their sizes in a wonderful manner. The drills used were carefully sharpened in one of the twist-drill grinders mentioned above.

In London upwards of 3000 holes were drilled $\frac{5}{8}$ in. diam. and $\frac{3}{8}$ in. deep, through steel bars, by one drill without regrinding it. The cutting speed was in this instance too great for cutting steel, being from 18 to $20 \mathrm{ft}$. per minute; and the result is extraordinary.

Many thousands of holes were drilled $\frac{1}{8}$ in. diameter, through cast iron ${ }_{16}^{7}$ in. deep, with straight-shank twist-drills gripped by an eccentric chuck in the end of the spindle of a quick-speed drilling machine. The time occupied for each hole was from nine to ten seconds only. Again, $\frac{1}{4}$ in. holes have been drilled through wrought copper, $1 \frac{3}{8}$ in. thick, at the speed of one hole in ten seconds.

With special twist-drills, made for piercing hard Bessemer steel, rail holes, $\frac{13}{16}$ in. deep and $\frac{29}{3} \frac{9}{2}$ in. diameter, have been drilled at the rate of one hole in one minute and twenty seconds, in an ordinary drilling machine. Had the machine been stiffer and more powerful, better results could have been obtained. A similar twist-drill, $\frac{2}{3} \frac{9}{2}$ in. diameter, drilled a hard steel rail $\frac{13}{16}$ in. deep in one minute, and another in one minute and ten seconds. Another drill, $\frac{5}{8}$ in. diameter, drilled $\frac{3}{4}$ in. deep in thirty-eight seconds, the circumferential cutting speed being $22 \mathrm{ft}$. per minute. This speed of cutting rather distressed the drill; a speed of $16 \mathrm{ft}$. per minute would have been better. The steel rail was specially selected as being one of the hardest of the lot.

\section{Mirling.}

The writer considers milling the most important system used in the cutting of metals, and would willingly dwell more upon it if time would permit. He will confine himself however to giving a few particulars as to the time occupied and the finish produced by milling machines, in comparison with the planing machine, the shaping machine, and the slotting machine. It is found practicable, and in most cases it is exceedingly advantageous, to finish (or as it is usually termed to "machine") almost every class of work, such 
as is now usually finished by planing, shaping, or slotting machines, in one or other of the numerous kinds of milling machines already in use.

It may not be generally known that in this class of machine milling cutters are being used of diameters ranging from $12 \mathrm{ft}$, used for heavy engine-work, ${ }^{*}$ down to $\frac{3}{4}$ in. or $\frac{1}{2}$ in., used principally for the intricate work required in sewing machines, small-arms, \&c. By the former, the work done is what is known as face-milling: the mill itself is somewhat similar to a large lathe face-plate, and the several cutting portions are steel tools inserted into it and firmly secured by a series of set-screws or keys. On the other hand, the milling cutters of the small sizes, from $\frac{1}{2}$ in. up to about 8 in. diameter, are made from solid blocks of cast steel, or blanks, as shown in Figs. 33 to 38, Plate 23.

The term "milling" is more generally understood in the United States than in this country. It means the cutting of metals by aid of serrated revolving cutters, each having a number of cutting teeth. Milling cutters have been used in this country for many years, but until recently with only a limited amount of success, owing to the expense and difficulty of producing their cutting edges and keeping them in order. This was next to impossible before the introduction of a machine, with a small emery-wheel and compound slides, \&c., for carrying the milling cutter whilst being re-sharpened. Hence in the old system of milling, which did not permit of the re-sharpening of the hard teeth, the results were, that after much expense and time had been bestowed on a cutter (including a quantity of hand-labour spent upon it while in its unhardened state), the whole was as it were upset by the process of tempering; the accuracy which had previously been imparted to it being usually quite destroyed by the action of the fire and sudden cooling. In some cases the cutter would be found slightly warped or twisted; in others it would be oval or eccentric; and most frequently, when set to work

* These large machines were designed by the late Mr. David Elder and by Mr. Alexander C. Kirk, and are in use at Messrs. John Elder and Co.'s Works, Glasgow. 
on a truly-running mandril in the milling machine, not more than one-third of the number of its teeth were found to bo cutting at all, the others not coming in contact with the work. This really meant that not more than one-third of the proper feed per revolution could be applied, and not more than one-third of the proper work produced. Nor was this the only drawback: the quality of the workmanship produced by such a milling cutter was not of the best, and deteriorated hourly from blunting and wear. Such a cutter would probably not work for more than two whole days before it would require to be again softened by being heated red-hot and allowed to cool gradually. The expensive and unreliable process of re-sharpening by hand-filing had to be gone through once more; then the re-tempering, which caused the cutter again to become warped, swelled, or eccentric; and each time it was subjected to the heat of the fire, it ran the risk of being destroyed by cracking when plunged into the cold bath.

It is necessary now to describe the modern system of making and maintaining the improved milling cutters. A cast-steel forging, or blank as it is usually styled, is bored, and then turned to its proper shape in a lathe. The teeth are then machined out of the solid to their required forms, in a universal milling or other machine. This work is so accurately produced, direct from the machine, that no costly hand-labour need be expended upon the milled cutter, which is taken direct from the milling machine to the hardening furnace, and tempered. The hole in the centre of the cutter is then carefully ground out to standard size, so that it may fit accurately and without shake on the mandrils both of the grinding machine and of its own milling machine.

The cutter or mill C, Fig. 39, Plate 23, is now placed on the mandril II of the small cutter-grinding machine; the mandril itself is adjusted vertically and horizontally by ordinary slides, and by means of a worm $\mathrm{W}$ and worm-wheel $\mathrm{B}$, to its required angular position; and each tooth is ground or re-sharpened by passing it once rapidly forward and backward under the small revolving emery-wheel $\mathrm{H}$. The mandril fits easily into the cutter which is being ground, so that the latter may be readily turned round by the thumb and finger of the operator. 
The exact mode of setting such cutters is as follows:-The clearance angle $\mathrm{L} J \mathrm{~J}$ on each tooth is obtained and maintained by the emery-wheel $\mathrm{H}$, of which a specimen is exhibited. The clearance is obtained by adjusting the centre $I$ of the emery-wheel $\mathrm{H}$ a short distance horizontally behind the vertical line D M through the centre of the milling-cutter. The shorter this distance D I, the less the amount of the clearance imparted to each tooth of the milling cutter $\mathrm{C}$. The upper dotted line $\mathrm{J} \mathrm{L}$ is a tangent to the circumference of the milling-cutter, drawn from the point of contact $J$; and the lower dotted line $\mathrm{J} \mathrm{K}$ is a tangent to the emery-wheel from the same point. The angle formed by these two lines is the angle of clearance.

Each tooth is held in its correct position by means of a stop $\mathbf{S}$, while the milling cutter is rapidly traversed once forward and backward under the emery-wheel. As will be seen by the arrows, the tendency of the emery-wheel is to keep the cutting edge which is being ground close up against the stop $\mathrm{S}$. There is no more difficulty in grinding spiral cutting edges than straight ones; and face and conical cutters can also be ground correctly, and with the same amount of ease.

Milling cutters are made of the required forms to suit the various shapes they are intended to produce; and all the ordinary forms can be used in any milling machine either of the horizontal or vertical class.

The face-milling cutters, Figs. 40 and 41, Plate 23, are of disc form, and are among the most useful. They are constructed to cut on one face and on the periphery; and they produce very perfect finish, especially on cast-iron. This form is also very useful for stepped work, which, even when not of the simplest form, can be readily and reliably finished to standard breadths and depths : so that. the pieces may be interchangeable, and fit together without the slightest shake or play, just as they leave the machine, and without any hand-labour bestowed on them.

Another ordinary and very useful form is the cylindrical cutter, Fig. 42, Plate 23, with teeth cut spirally over its circumference. This is largely employed for cutting flat, vertical, or horizontal surfaces, for finishing concave and convex curves, and for complicated forms made 
up of straight lines and curves. With this spiral arrangement of the teeth, and with reliable means of re-grinding or re-sharpening them, very high-class machine-work can be produced. Some experiments have been made by cutting a spiral groove or thread into the outer surface of one of this class of mills, and thus reducing the aggregate length of its cutting surface. The results appear to be practically as follows:-If half the length of cutting edges are dispensed with, only about half the maximum feed per revolution of the cutter can be applied by the machine; if three-quarters of the length of the cutting-lips are left intact, three-quarters only of the aggregate feed can be used; and so on in the same proportion.

Other mills again are made in the form of small circular saws, varying from $\frac{1}{4}$ in. to $1 \frac{1}{2}$ in. or more in thickness. The teeth in some of these are simply cut around the circumference; others have these teeth extending some distance down each side, their edges radiating from the centre of the mill, as in Figs. 43 to 45 , Plate 23. Towards the centre they are reduced in thickness so as to clear themselves. These cutters are useful for a very great variety of work; for instance the cutting of key-ways, parting off or cutting through pieces of metal, and making parallel slots of various widths, for the broader of which two or more cutters may be used side by side.

Conical and angular milling-cutters, Figs. 33 to 38, Plate 23, are much employed for a great variety of work, such as the cutting of rymers, the making of milling cutters themselves, bevelling, cutting the serrated part of hand- and thumb-screws, nuts, \&c. Figs. 34 to 37 are edge views of four of these cutters; Fig. 33 is a face view, and Fig. 38 a section of one of them.

Any complex forms, such as the spaces between the teeth of spur, mitre, and other wheels, can be machined by using what are known as the patent cutters, which can be re-sharpened as often as required by simply grinding the face of each tooth. They are so constructed that, however often they are re-ground, they never lose their original curved forms, and always produce the same depths of cut. One of these cutters, for instance, will eut the same standard shapes of teeth in a spur-wheel, after it has been used for years, as it did the first day it was started. 
There is risk of fracture in making large milling-cutters out of one solid cast-steel blank, the principal difficulty being in the tempering. In practice it is found that if they are required of larger diameter than about 8 ins. they are better made of wrought-iron or mild-steel discs, with hardened cast-steel teeth so securely fitted into them that they do not require to be removed. The cutting edges can then be re-sharpened in their own places, as in the case of the ordinary milling-cutters; thus ensuring that each shall have the same angle of cutting and clearance, run perfectly concentric, and therefore do a maximum amount of cutting in a given time. It must however be borne in mind that the smaller the diameter of the milling-cutter, the better finish it will produce; and cutters of large diamoters should only be used to reach into depths where one of smaller diameter could not, or to do the heavier classes of work. Again, the smuller the cutter, the less does it cost to make and maintain.

The writer has not had an opportunity of actually testing the relative amounts of engine power required for driving milling machines ; but, as far as he can judge from ordinary practice in doing ordinary work, he has not perceived that any more power is required to remove a given weight of shavings than that required for a lathe, planing machine, or shaping machine, with efficient cutting tools in each case.

The cutting speed which can be employed in milling is much greater than that which can be used in any of the ordinary operations of turning in the lathe, or of planing, shaping, or slotting. A milling cutter, with a plentiful supply of oil, or soap and water, can be run at from 80 to $100 \mathrm{ft}$. per minute when cutting wrought iron. The same metal can only be turned in a lathe, with a tool-holder having a good cutter, at the rate of $30 \mathrm{ft}$. per minute, or at about one-third the speed of milling. Again, a milling cutter will cut cast steel at the rate of 25 to $30 \mathrm{ft}$. per minute.

The increased cutting speed is due to the fact that a milling cutter, having some thirty cutting points, has rarely more than three of these cutting at the same time. Each cutting point therefore is only in contact with the metal during one-tenth of each 
revolution. Thus, if we suppose it is cutting for one second, it is out of contact, and therefore cooling, for the succeeding nine seconds, before it has made a complete revolution and commences to out again. On the other hand, a turning tool while cutting is constantly in contact with the metal; and there is no time for it to cool down and lose the heat imparted to it by the cutting. Hence, if the cutting speed exceeds $30 \mathrm{ft}$. per minute, so much heat will be produced that the temper will be drawn from the tool. The same difficulty to a great extent applies to the cutting tools in planing, shaping, and slotting machines. The speed of cutting is governed also by the thickness of the shaving, and by the hardness and tenacity of the metal which is being cut: for instance, in cutting mild steel, with a traverse of $\frac{3}{8}$ in. per revolution or stroke, and with a shaving about $\frac{5}{8}$ in. thick, the speed of cutting must be reduced to about $8 \mathrm{ft}$. per minute. A good average cutting speed for wrought or cast iron is $20 \mathrm{ft}$. per minute, whether for the lathe, planing, shaping, or slotting machine. 


\section{COMPARISONS OF TIME OCCUPIED IN ROUGHING-OUT}

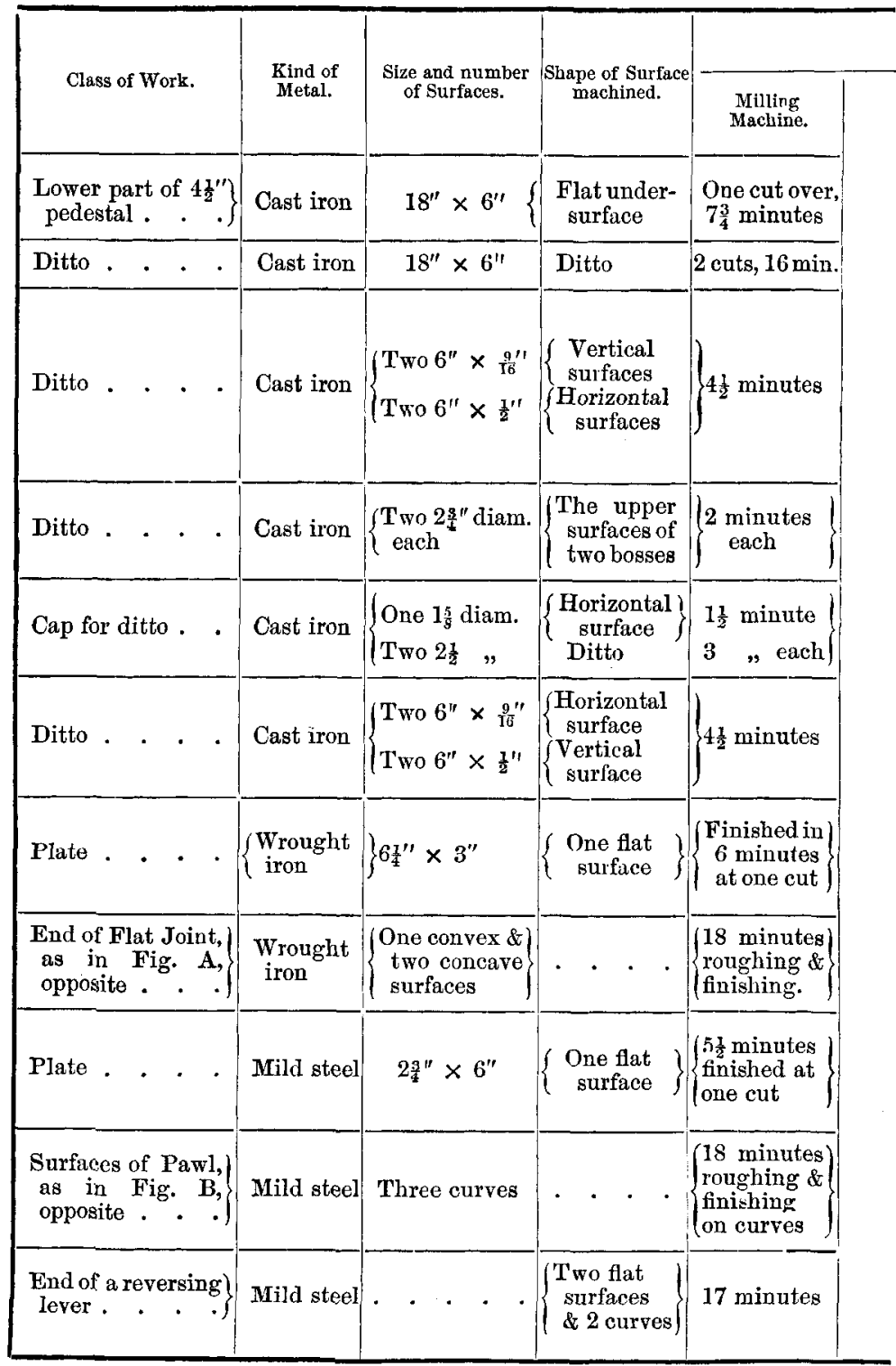


AND FINISHING METAL SURFACES IN MACHINE TOOLS.






\section{Abstract of Discussion on Modes of Cutting Metals.}

Mr. Ford SyItr exhibited and explained many of the tools referred to during the reading of the paper; also specimens of work done by various tools; and two machines, one for grinding milling cutters, and the other for grinding twist-drills. He also referred to the accompanying Table, page 250 , which gave the speeds at which some of the work exhibited had been produced. The experiments described in this Table had been made principally to test the speed of milling against that of shaping, planing, slotting, or turning. For instance, the lower portions of two pedestals had been one of them shaped, and the other milled with a milling cutter. The time occupied on the former had been $11 \frac{1}{4}$ mins. for each surface once passed over, and on the latter 8 mins., the area being $18 \mathrm{in.} \mathrm{by}$ 6 in. The other experiments were of a similar character. In another case, of two wrought-iron forgings for the ends of flat joints, shown at Fig. $\Lambda$ in the Table, one was given to a man at the milling machine, and the other to one of the best slotters in the works. These men knew that they were working against each other, and did their best; and the time came out, with the milling machine 18 mins., and with the shaping machine 44 mins., which was a great disparity. One reason was that the latter required three settings, as almost all such convex and concave curves did; first it had to be set so as to finish into the corner $P$, then into the corner $Q$, and then a third setting was needed for going round the outside convex surface. When a milling cutter large enough in diameter to form the corners could be used, it could be set to machine the required breadth, and, by once feeding it round the end of the joint, finish it. Again, facsimiles of the pedestals referred to at the top of the Table-which had been produced in large quantities - were all machined so absolutely to standard breadths and depths, direct from the milling machine, that, for instance, any cap would fit any lower piece with such perfect precision as to be quite free from shake, and thus require no fitter's hand-labour to be spent upon it. In other words the 
lower pieces and the caps were interchangeablo; and as the under surface of each pedestal had also been milled over-the milling system having been employed throughout-the height of the centre of each pedestal from its base was ensured correct to one standard uniform measurement. Such accurate results could not possibly be produced in the same short space of time by any other means. Reference to the Table, page 250, showed $4 \frac{1}{2}$ mins. for milling against 38 mins. for shaping, for the parts of each cap and each lower piece, where they fitted together.

Mr. J. H. WICksteed said the question of drills seemed to him to be not entirely worked out in pp. 236-239. There was part of an ordinary drill, close to the point P, Fig. 26 , Plate 22, which did not cut at all. If it was looked at from below, as in Fig. 28, there was an oblique line $I J$, forming the connection of the two ground edges of the drill. That line $I J$ was not cutting; it merely ran round and rubbed; and that was the part which required all the force on the top of the drill to drive it into the metal. However much the cutting angle of the drill might be improved at the edges PM, PN, Fig. 26, that would not improve the connecting line IJ, Fig. 28; hence in any material, if you had a small core-hole to start with, you could employ at once a feed four times as rapid as you could employ when drilling through a solid piece. However quickly the drill was rotated, it did not give too high a cutting speed at the point P, Fig. 26; it was too near the centre for that. Therefore he was not quite sure whether Mr. Ford Smith's system repaid him for his trouble, and for the extreme accuracy required in arranging the cuts; because it was not for the sake of the cutting edges, even if they were not particularly good, that you needed so low a rate of downward feed as one hundred cuts to the inch; but it was for the sake of preserving the point, and giving it time to force itself into the metal, that you were obliged to employ fine feeds.

He was a little surprised at Mr. Smith's proportion of feed to number of revolutions. He made the drills revolve with a circumferential speed of about $20 \mathrm{ft}$. per minute, and gave them. about 100 revolutions to the inch of downward traverse. He himself 
should have used 200 revolutions to the inch of downward traverse, and a cutting speed of $40 \mathrm{ft}$. per minute, in cases where water could be used.

With regard to the rests, he would ask members to look at the swivel tool-holder, Figs. 1 and 3, Plate 19, and compare it with an ordinary slide-rest, as in Fig. 12A, Plate 20. In the latter the whole of the tool was bearing on the rest, and that was down upon the bed of the lathe, and held to it by the V's. It was quite clear that the tool was supported under its heel, and could not spring away from the cut. That was the right position-for taking a heary cut without jar. Not only was the tool supported under the heel, but the rest was supported by the lathe bed, and the point of pressure was not outside the point of support; so that there was no tipping action against the inverted $\mathrm{V}$. $\mathrm{H}_{\theta}$ did not see that the arrangement of movable tools lent itself so well to heavy cuts, although it facilitated getting a thoroughly good edge, and was first-rate for giving the high finishes which Mr. Smith produced. There were also a great many instances where you must have an overhang, whether you liked it or not, for instance, with a parting tool ; and there Mr. Smith's form of tool-holder was right, and convenient. Thus the parting tool, Fig. 9, Plate 20, was in a very good position, because the spring that inevitably took place when the tool projected beyond the support, took place in the direction indicated by the dotted arc $P Q$, with the centre $\mathrm{C}$, and tended to relieve the tool out of its work, instead of making it dig into it. Again, if you were roughing with a tool in a strong planing machine, and could bring the planing-machine box down to the position shown in Fig. 9A, Plate 20, you were in the best position for taking a heavy cut. But if you were obliged, for the sake of a parting cut, to make the tool project below the tool-box, that tool should be of the form shown in Fig. 9; otherwise, since the spring of the tool would come from $\mathrm{C}$, the point of the tool would gather into the work, as shown in Fig. 9B. But with $\mathrm{Mr}$. Smith's tool, having thrown the tool back to the position shown, the point of the tool relieved itself; and you could get on a great deal better for that reason. He had no doubt that this was the explanation why the composite tool in the particular experiment given first in the 
Table, page 250, got on nearly twice as well as an ordinary solid tool, which was probably made as indicated in Fig. $9 \mathrm{~B}$.

Mr. Anthur Paget wished to ask Mr. Ford Smith whether there was any means at present in use of obviating the one defect which he had constantly found to exist in twist drills. It was very analogous to the defect pointed out by Mr. Wicksteed in the old form of flat drill-namely that the front part of the drill, on the line IJ as shown by Mr. Wicksteed, Fig. 28, Plate 22, did not cut the metal at all, but was forced into it by a sort of bruising or crushing action; but he had imagined that nobody but the traditional village blacksmith now made flat drills according to the form shown by Mr. Wicksteed. Flat drills should always be made to the shape shown in Figs. 27A and 28A, Plate 22, thick at the shoulders of the drill and coming to a thin edge at the point. The drills in his works, for the last twenty years, had been made to that shape; and then there was very little of that forcing the point into the metal which $\mathrm{Mr}$. Wicksteed had spoken of. The only difficulty that he had noted in twist-drills was that there was in these drills no means of reducing the blunt point (or line IJ, Fig. 28, Plate 22), between the two grooves, which did not cut at all, but merely squeezed itself into the metal. There must be proportionately much more work concentrated on that little spot than on all the rest of the metal being drilled. He should be glad if Mr. Ford Smith could tell them of some means of obviating that defect. It was of more importance in small drills than in large ones; because that blunt point (or line IJ) in the smaller drills bore a much larger proportion to the whole area.

Mr. William Anderson wished to compare the finish of the two specimens of flat joint-ends, Fig. A in the Table, p. 251, one made with a milling cutter, the other in a shaping machine. He could tell by feeling, with his eyes shut, which was which. The one that was done by a milling cutter was all in ridges, and the one done by the shaping machine was quite true and smooth. The author had been comparing the cost of the two processes; but such comparison could not fairly be made, becnuse the quality of the work 
was so different. If appearance were all that was wanted, the comparison might hold; but for real quality of work, necessary for instance if the joint ends were meant to work against a bearing, the shaping machine had alone done satisfactory work.

Mr. Daniel Longworth said the author stated, p. 227, that he liad adopted one cutting angle both for cast and for wrought iron, simply for the purpose of having uniformity. But all writers on the subject, and those who had experimented in the workshop, had come to the conclusion that two angles were really necessary; and sometimes even more, according to the hardness of the material. He wished to ask Mr. Smith what angle he had finally adopted, as in his former paper he had taken $50^{\circ}$ for wrought iron and $60^{\circ}$ for cast iron. In the paper reference was made to broad cutting; and he should have thought that the angles shown in Figs. 1 and 3 would not do very well for broad cutting.

He thought Mr. Smith deserved credit for again drawing the attention of engineers to the great importance of having uniformity if possible in their workshop tools. At the same time the author perhaps gave more credit to the tool-holder than was really due to it. The success obtained, p. 234, was rather due to the accuracy of the cutting edge; for in comparing work done by the tool-holder with work done by one of his workmen with an ordinary tool, Mr. Smith's superior knowledge of the best cutting edge in that particular case had been put against that of the workman. No doubt, if the one tool had had the same cutting edge as the other, the result would have been precisely the same.

Another question he wished to ask was whether Mr. Smith had succeeded in dispensing with the rose bit; that is, in making holes, by the drill alone, to fit accurately a pin turned to gauge. If he had done that, he had certainly made a great step in advance; because in ordinary work, where a pin was required to fit a hole accurately, it was necessary to use a rose bit, even after the hole had been drilled by a twist-drill ground carefully by hand.

As to milling cutters, Mr. Smith was right in stating that the introduction of the little emery-wheel and its attachments for 
sharpening the cutters had been one of the greatest improvements made. Milling machines had been tried, to his own knowledge, fifteen years ago for grooving steel; and they were abandoned after great expense had been gone to, because of the difficulty and cost of sharpening and maintaining the cutters. Mr. Smith had not shown any samples of brass-work finished by milling. Milling had been tried from time to time for brass, but had never succeeded to any extent, because of the difficulty met with in the grooves getting clogged up, and because the ordinary single fly-cutter or tool was durable and accurate enough for most purposes. He should like to ask therefore if the author had made any improvements in milling brass. For cutting cast iron to standard forms the milling cutter was the best tool to use; he knew of cases where small milling cutters were successfully employed on cast iron at a speed of 250 feet per minute.

Mr. Jeremiah Head thought they had scarcely yet complimented Mr. Smith sufficiently on his valuable paper. Papers of that kind, even although they might contain nothing absolutely new, yet if carefully worked out, as Mr. Smith's had been, certainly did an enormous amount of good, by spreading among the whole body of the members information which, so far, might have been confined to a few. But Mr. Ford Smith had done more than that. He had concentrated his attention on a department of mechanical engineering which was of extreme importance, although it had hitherto attracted but little attention. That department included the form and maintenance of cutting tools, the work they would do in a given time, and so forth. He noticed that Mr. Smith had not said anything about the kind of steel which he used or recommended for tools; but he gathered from the general tone of his remarks that his desire was to aroid smith work as much as possible - to take a piece of steel which was originally of the proper hardness and temper, and, if possible, to use it up simply by grinding it gradually away. Now it was well known that there were certain alloys of iron and other elementary substances forming steels, such as chromium stcel, titanic steel, \&c., with peculiar characteristics. There was also "Mushet's special steel," 
which was said to be more enduring than ordinary cast-steel; and it would be interesting to know whether Mr. Smith's arrangements necessitated having steels of these or any other special kinds.

With regard to the term " milling," he remembered many years ago that it was used simply for a little tool that made a serrated edge on small nuts in brass work. He presumed that the carrying on of the name to a kind of work, which was entirely different, had come from the tools used in the two processes somewhat resembling one another. The paper seemed to show that milling in its new sense had been wonderfully perfected in recent years, and for many operations, in engineering work, was destined to supersede ordinary cutting tools.

Mr. JoHN Frelding agreed with Mr. Head in thanking the author for the able manner in which he had brought his paper before them; but he should like to ask him some questions about the maximum speed he had been able to obtain in cutting with his tools. As bearing upon that question, he had brought with him two cast-iron tools having chilled points. While he did not assert that the use of cast iron for tools was new (it was really very old), he should like to ask why it had not come more generally into use. The tools were simply copies of an ordinary forged tool, cast with a piece of iron in the mould to chill the face; and with these tools he had been able to turn cast iron, wrought iron, and gun metal at speeds from 50 to 100 per cent. greater than with the best special steel. His firm had tried Mushet steel, as good as they could get it ; but with cast-iron tools they had been able to do from 50 to 100 per cent. more work. It had struck him, in hearing Mr. Smith speak of broad-finishing cuts, that cast-iron chilled tools were applicable for such work, because you could thus get a heavy tool at a minimum cost. A broad tool necessarily meant a heavy tool, in order to get sufficient rigidity (to which Mr. Smith rightly attached great importance): and the crtting edge in chilled iron being extremely hard, it would stand its work very well, as was shown by the fact that cast iron was used in turning chilled rolls. While such tools could not compare with Mr. Smith's as a complete system, he thought they afforded some 
advantages in heavy cutting. They were able to furnish the correct angles at a moderate cost, about $1 d$. per pound, whereas the cost of steel was twelve or fifteen times that amount.

With regard to milling machinery, the value of that part of the paper would have been vastly enhanced if it had shown the different forms of machines used, both with vertical and with horizontal spindles, and had described how they would replace slotting, planing, and shaping machines.

Mr. JoHN Robinson joined with Mr. Head in thanking Mr. Ford Smith for bringing before them the means of arriving at correct cutting angles. He had no doubt that Mr. Smith would remember the "revolving cutters," as they were then called, which were formerly in use at the Atlas Works in Manchester. All the surfaces of four and six-sided nuts were dressed by that process, now improperly called milling. Another operation which at that time they carried out by the same means was that in cranked axles, after being forged quite solid, the two cranks were then cut out with the milling tools. Afterwards, he scarcely knew why, slotting tools were used for the purpose; and then the pieces left were taken out by means of a drill. On the whole he believed the milling process was the most economical ; but the difficulty (which Mr. Smith seemed to have got over by the methods he had adopted) had been to keep the cutters in sufficiently good order. They had formerly no such thing as the grinders, which had been invented of late years; and the process of sharpening up and hardening was very tedious and very expensive.

With reference to some of the forms of cutters-for instance Fig. 8 and Fig. 10, Plate 19-he should like to ask whether the cutter in Fig. 10 had not been forged to the form which it possessed, in order to take the under cut. The cutter in Fig. 8, although it was "necked" in, as they would say in the North, seemed probably to be worked by simple grinding from an ordinary form of tool steel. With reference to such forms as in Fig. 9, Plate 20, which was a planing-machine tool, it seemed to him that the number of joints through which the stress on the tool had to pass, before it met 
with the ultimate resistance of the cross-head, was considerable, and likely to create jarring. He admitted that all the other joints, except those on the tool itself, existed before, and were necessary in order to get the requisite motions; but now there were two or three other surfaces of division, which would have to be taken into account. He should like to ask Mr. Ford Smith whether in practice he found it difficult to keep those surfaces so tightly bolted up as to prevent a jar in the tool, when it was cutting a surface in the way shown in Fig. 9. The same observation applied perhaps to the swivelling tool-holder, Fig. 3, Plate 19. It was exceedingly ingenious; still every one knew that such implements, when screwed up by workmen who were not so careful as they should be, were liable to get out of order. The forms of steel used for the several cutters represented in the drawings showed that Mr. Smith had taken all possible pains to produce nicety of work; and he could not but speak highly of the desire shown to keep the tools out of the hands of the smith, not only because of the expense of forging, but also to preserve the original temper of the stecl, when that temper was well adapted to the object in view.

The mode of grinding in Fig. 39, Plate 23, was exceedingly ingenious, and showed how inexpensive the actual processes were, if only you had money to buy the tools first, and men to work them well afterwards; because, after all, it was a kind of machine that could not advantageously be put into a shop, unless it was carefully looked after by trustworthy men. The whole system was one which required organisation, a point in which Englishmen often fell behind their continental brethren. Mr. Smith had done wisely to arrange the system, and bring it to them ready cut and dried; and the only thing to be done was to persuade people to take it up and follow it out.

With regard to cast-iron tools, what seemed to him to bo a disadvantage in them was, that they could not be ground up very frequently. It was easy to make a casting from a pattern, but the cutting angle would soon be ground off, and then the whole mass of cast iron was thrown away, in regard to its usefulnoss as a tool. But in the form of tool which Mr. Smith had shown, the 
tool could be worked up until it was too short to be held in a holder ; while nine-tenths of the cast-iron tool had to be thrown away.

Mr. Freiding asked leave to make a remark with reference to the last point that Mr. Robinson had mentioned. By chilling $\frac{3}{8}$ in. deep, the tool would wear for a very long time; and when it was worn away, the cost of melting it up, and running it into a mould again, was much less than the cost of forging a fresh tool.

Mr. W. W. Hulse thought they must all admire the tenacity with which Mr. Smith and his firm adhered to the question of toolholders. That subject was one in reference to which there had been a good deal of experience at the works of Messrs. Whitworth \& Co. From time to time it was resuscitated, but it always had to be as it were flogged into activity. The tool-holder, no doubt, was a valuable thing, but it was very limited in application to general workshop practice. One reason he supposed was that engineers looked every day more and more not merely to polishing the outside of a piece of metal with a machine tool, but to doing a large portion of the work which was formerly left to the forge. He had with him some cuttings which were taken from a lathe recently made by his firm; these showed what description of cutting was expected of a machine tool in the present day; and he would ask any one to say whether any form of independent tool-holder could support a cutting tool that would deliver cuttings of that kind. The euttings were just as they came from the lathe, off a piece of good tough steel, $28 \mathrm{in.}$ in diameter, cut at the rate of 6 feet per minute circumferential speed; they were about $1 \frac{1}{2}$ in. deep by $\frac{1}{4}$ in. thick, the traverse being $\frac{1}{4}$ in. in each revolution. That was what the modern lathe was expected to do, and no tool-holder had been introduced that could do it (unless the slide-rest might be called a tool-holder), nor anything but a solid bar of steel, $2 \frac{1}{2}$ or 3 inches square, absorbing the heat as it was generated. The twist-drill no doubt was also a very excellent thing; and Mr. Smith's firm deserved credit for the tenacity with which they kept those small tools in view; but he had recently had sent to him some samples of cuttings from a new drilling machine, 
just made, for dealing with the couplings of propellers, in which the bolt holes were to be drilled out of the solid, each at one operation. The cuttings came from a flat drill, 3 in. diameter, at the rate of $\frac{1}{6 \sigma}$ in. per revolution, and they were equal to if not greater than anything that would come from a twist-drill. No doubt one advantage of the twist-drill was the maintenance of shape and size; but the readiness with which the workman could deal with a flat drill would, he was afraid, keep it always in the workshop. That milling or (speaking more correctly) circular cutting machines would displace planing, shaping, and slotting machines, he did not believe. Circular cutters certainly had their uses, notably for articles of which a large number were required; but the bar tool was ready at all times for any change of form. The planing, shaping, and slotting machines, with bar tools, could undoubtedly produce truer planes than circular cutting machines, unless in the latter case each tooth of the revolving cutter acted throughout its whole length upon the surface to be planed, or unless all the teeth revolved in one plane, which in practice could not be ensured after hardening. Nevertheless circular cutting machines, if properly arranged so as always to keep a firm hold on the revolving cutters, were most useful additions to engineering workshops, especially for shaping frequently repeated articles and forms; and for such work, where the configuration was principally to be considered, the circular cutting machine was undoubtedly most expeditious and sufficiently accurate.

Mr. J. HAWTHonN Krrson said that for some time he had been working with revolving cutters of considerable dimensions; and he had put on the table two specimens of the kind of work they were doing. One was a cross-head, the jaws of which were cut out of the solid with two cuts of a revolving cutter. It was done at a very considerable speed, and after the first cut there was only about $\frac{1}{8}$ in. left for the second cut. It would be seen that the finish was as good as could be desired. The other specimen was a large eccentric joint. They had previously tried punching out the middle of the joint under the hammer; but they found that with a set of cutters, 
cutting out the middle, and finishing the two outside faces at the same time, they could work as rapidly cutting out of the solid, and it was decidedly cheaper. The finish was not perfect; but a file, or something like it, had to be applied to all such work for its final adjustment, as the work altered its shape when cut out; and the cutter gave what they considered a sufficiently good workshop finish. The work had also been milled all over outside.

The paper stated, p. 247 , that a cylindrical cutter with a spiral groove dividing the teeth would not do as much work as one with solid teeth. But he had found that for roughing work, they could take double as great a cut, either in depth only, or in depth and traverse combined, with the grooved cutter, Fig. 46, Plate 24, as they could with the plain cutter. In finishing work, they required to have the solid cutter. On some of the foreign railways milling had been studied very minutely and scientifically. Figs. 47 to 49 , Plate 24, showed a French cutter sent to him from the Paris and Lyons Railway. It was found that the angle of the teeth was a question of very great importance; and after careful study the conclusion arrived at was that the pitch should be six times the diameter. The tool diä very beautiful work, but only at a quarter of the speed at which the work could be done with the grooved cutters, Fig. 46. The latter broke off pieces $\frac{1}{4}$ or $\frac{3}{8}$ in. wide, instead of long thin shavings, and the cutters seemed to relieve themselves in that way.

The President said, before asking Mr. Smith to reply, he would say a few words. He could confirm all that Mr. Smith had said, and even more, with regard to the advantage of milling. First, as to the endurance of the tool. If the tool were held firmly, without vibration, it would last an extraordinary length of time. The inequalities that were noticed in milling were not due to the tool but to the machine, the parts not being sufficiently strong and rigid to prevent vibration. A remark had been made by Mr. Anderson with regard to two pieces he held in his hand, that he could tell with his eyes shut which was which. In that case probably the spindle which held the cutter was too weak, or else the rest in which it was held vibrated, producing the ridges which were felt by the 
touch; but, where the tool was firmly held, he had seen milling turn out work as accurately as slotting or planing could do. $\mathrm{He}$ believed that there was a great future for milling. With regard to the question of endurance, he had one tool which had been in constant use for eighteen months, with a little grinding up occasionally; and it still did its work admirably. Of course they were expensive tools to get up ; and great care should be taken to get a good steel, and to anneal it properly. He could confirm Mr. Kitson's statement with regard to the grooving of cylindrical milling tools. He found that for rough cutting, the groove certainly did enable them to take a heavier cut than they could take with the plain tool. A question had been asked by Mr. Longworth as to the milling of brass. His experience was that tools such as were shown in the drawings, which were for cast-iron or wrought-iron, would not answer for brass; a greater pitch between the teeth and a higher speed were necessary for brass.

He thought Mr. Ford Smith's perseverance in carrying out all his arrangements deserved great credit. Some years ago, when endeavouring to introduce the system, he himself had found that, in a shop where there was a great variety of work, heary and light, they were not able to carry it out thoroughly; but they still used a good many of the tools for certain work. For really heary work the system did not answer so well, and chiefly for this reason, that in very heavy work it was absolutely necessary to have a large, heavy tool, and to have the point supported immediately underneath by the rest-in fact to make the whole as rigid as possible. It was also necessary to have plenty of steel in the tool, to carry off the heat indnced by a heary cut. In the tools described in the paper, where there was necessarily an overhang, and where the tool-holder was composed of several parts, there was not sufficient rigidity to take off a tearing cut.

Mention had been made of Mushet steel ; and for some purposes that steel was unsurpassed. It was a very peculiar metal. It had to be worked up to a good heat and simply allowed to cool in the open, and it must not be tempered or used with water. It did not do its work properly until it had got fairly hot. In one machine, used for turning up hydraulic rams, with three tools-two rough cuts and a 
finishing cut-they had turned with one set of tools eleven rams, $10 \mathrm{in}$. diam. and $12 \mathrm{ft}$. long; they never touched the tools once, putting in ram after ram, and the last was as good as the first. But that machine gripped the work like a bull-dog, so that there was no vibration between the tool and the work.

With regard to drills, he did not look upon the twist-drill by any means as a universal tool. For some purposes the flat drillif properly made, with the same care and precision as were expended in making twist-drills-was superior. Hitherto one of the great advantages of the twist-drill had been that so much care and pains had been expended in getting it up; but he had found that, using flat drills, and taking the same amount of care to ensure the sides being parallel and tho angles cut even, and also pointing the edge truly so as to do away with the blunt nose, the drill would work freely, and the shavings come off even better than from the twistdrill. In drilling through cast-steel, about 11 in. deep, he had seen shavings coming out, on either side of the drill, from 10 to $12 \mathrm{in.}$ long, or even more; and he did not think that a twist-drill would enable them to accomplish that. There was of course this difference between the plain drill and the twist-drill, that in forming the latter you sacrificed a great quantity of material in cutting out the groove; and it was of course a much more expensive tool to get up. In the flat drill there was very little waste of material, and it could be drawn down when it got too short; whereas when a twistdrill got too short, it became valueless. In going through bad castings however, there was no doubt the twist-drill wonld make a straighter hole.

Mr. PAGET asked leave to put a question as to the objection made to the tool-holder, namely the want of a mass of metal to take away the heat. A former member of the Institution, the late Colonel Clay of Liverpool, had produced some years ago before the Institution (Proceedings 1872, p. 288) a tool with a hole bored through it, so that water could be made to pass along the inside to absorb the hext. He wished to ask Mr. Ford Smith whether he had tried that plan in connection with his tool holder. 
The President said he had found that the less one dealt with water the better. If steel of sufficient size were used, very little water was required; in fact, cutting steel with steel, water was not wanted at all. With regard to cast-iron tools, he might say that he had tried them only for castings which were so exceedingly hard that steel would not touch them. But, for the reasons given by Mr. Robinson, he did not think they were universally applicable.

Mr. Thomas R. Crampton asked permission to say a word upon some experiments he had made to show the bad effects of jarring, when using revolving disc-cutters for shaving off chalk or stone. He found that, when the cutters and cutter-head were too light, the material was simply disintegrated; but when the whole was firm and solid, shavings were cut off quite smooth even in sandstone, which was so easily broken when thin. The shavings on being out ran up the revolving cutters like ribbons. The firmness of the tool also reduced considerably the power required to do the work.

Mr. W. Fond SmITH in reply said that Mr. Wicksteed had alluded to the thickness of the point of the drill being an objection, and Mr. Paget had also referred to the same subject. The difficulty of boring with a large drill which had a thick point was by many engineers overcome by first drilling a small leading hole, and afterwards opening it out to the required size by using a large drill, the point of which, entering into the small hole, had no cutting to perform. There were two objections to that plan; the first being that the point of the larger drill, not having any metal before it to support and steady it, was free to run eccentrically, oscillate transversely, and revolve with a series of jerks, thus producing a badly finished hole, which upon examination would be found to be much jarred, and anything but round. The second objection was that it was too tedious and expensive to drill a small leading hole first, as a considerable amount of time would be occupied in changing the speed of the drilling machine from the slow speed, which had last been used for the larger drill, to a speed quick enough for drilling advantageously the smaller or leading hole. The change of speed 
entailed the altering of the strap on the cones of the drilling machine, and in many cases the disengaging and again engaging of the double gearing of the machine. Both these objections were surmounted by using a twist-drill. If preferred, its point might be thinned down, in a grinding machine with small emery-wheel, to any degree of thinness which might be found best for penetrating without fracturing as in Fig. 29A, Plate 22; this was a simple mode of reducing the blunt end between the two grooves to any extent, thus meeting the requirements of Mr. Paget. By this system the point only needed to be thinned after about every sixth time the lips were re-ground; of course each re-grinding of the lips gradually caused the point to become thicker, until it was found advisable to reduce it again by grinding. With this system very heavy feeds might be employed, and a twist-drill 2 in. diameter had drilled one inch deep in wrought iron for every 62 revolutions; such a feed however he considered too heavy for every-day practice, and he preferred to use a feed, for drills over $\frac{1}{2}$ inch diam., of 100 revs. per inch, as given in the paper, and not 200 revs. per inch, as suggested by one of the speakers.

While agreeing with Mr. Wicksteed that the less overhang a cutting tool or tool-holder could have the better, yet in actual workshop practice it was found impossible to avoid overhang altogether; and it would be found in going the round of any works, say for example the machine shop of a marine-engine builder, that probably forty-nine out of every fifty tools .were obliged to overhang the slide-rests or the tool-boxes which carried them-in most cases to the extent of many inches of overhang-in order to reach the part which had to be operated upon. In numerous instances the cutting tool had to reach into deep corners and recesses, often as much as one or two feet deep : the tool or tool-holder having in many such instances to be made specially long. The few cases where overhang could be dispensed with were in turning a long hydraulic ram in a lathe, or a large straight propeller-shaft: the slide-rests of the lathe could then be brought almost touching the work, as in these examples there were no projecting arms, bosses, or anything of that sort to prevent it. Where however it was desirable to avoid overhang, the swivel tool-holder could be cramped diagonally on the 
rest or tool-box; and even though a cutter of great length were then used, it might project as short a distance out of the holder as desired, so as to overhang not more than $\frac{1}{4}$ or $\frac{1}{2}$ inch, as illustrated in Fig. 50, Plate 24. Again, where in some special case exceedingly heavy cutting was required from the round tool-holders, then if it was considered advisable a narrow portion of the front part of the rest or tool-box might be recessed for the curred part of the tool-holder to lie solidly in, as shown in Figs. 51 and 52, Plate 24. By this means the round cutter might be brought up so close to the front of the slide-rest as almost to touch it; or else the old style of straight tool-holder could be used, drawn back on the top of the rest until there was no overhang. For such heavy cutting the tool-holder and cutter must also be sufficiently heavy and massive to convey the heat away. There was no particular limit to the size the tool-holders might be made; and they were all constructed of steel.

To test the stability and cutting powers of round tool-holders, he had made an experiment in a heavy 15-in. treble-geared lathe with 5-ft. face-plate, turning a hard Bessemer-steel shaft 8 in. diameter with a traverse of $\frac{3}{8}$ in. to each revolution. Care was taken to examine the amount of spring which really took place in the short overhanging portion of the tool-holder; a gauge was applied, resting on the solid saddle of the lathe, and high enough nearly to touch the cutter. Very little spring was discovered at this point, the sliderest and tool-holder proving to be more stable than other parts of the lathe. The loose headstock, though very massive and secured to the bed by three large holding-down bolts, proved to be the weakest part of the lathe; its centre could be seen perceptibly to spring and rise when the cut was put on.

For roughing out very heavy iron and steel forgings, such as Mr. Hulse had alluded to, there was no doubt that the most speedy and least expensive system was to employ powerful machine-tools. From his own experience this applied also to smaller articles, such as pins and set-screws with collars and heads, studs, \&e., which were roughed out and finished direct from the black bar-iron and then cut off: the whole being accomplished at one setting, and expensive smith's work being entirely aroided. 
Mr. Anderson had referred to the finish of two joints, and asked which was the best. To all appearance the milling gave the finest finish; but by passing the fingers carefully over the milled part very slight undulations could be detected. This was simply because there was only one vertical milling machine at liberty to do that work at the time, and it was far too light and delicate for the purpose. Its circular table, which carried the joint, was only about 8 in. diameter; while the table of the slotting machine on which the corresponding joint was finished was about $24 \mathrm{in}$. diameter, and the machine proportionately heavy. The fact however must not be lost sight of that the milling was done in one third of the time occupied for the slotting. Milled work generally was better finished than shaped or slotted work: take for example the admirable specimens of workmanship sent from America, such as lathe and drill chucks, \&c., which were finished direct from the milling machine with such wonderful accuracy that any hand-labour bestowed on them would only injure the fit; and this would apply to a great extent to the larger work. There was no reason why he should be biassed in favour of milling any more than of slotting or shaping: all he desired was to produce work in the best way and at the cheapest rate.

Mr. Longworth had asked why he did not adopt two cutting angles-one for cast metals, the other for wrought metals-as in the case of the round tool-holders. The objection to doing so was that there would have been much more complication, as double the number of tool-holders and cutters would have been required. The question had also been asked whether broad-cutting could be done with the tool-holder as correctly as with an ordinary tool. All he could say was he was constantly doing broad-cutting with tool-holders, and found that the machined work was better than he could produce by any other means in the planing machine. It was advisable in this case, when grinding the cutter, to give it as little clearance as possible. One of these cutters, which he had examined in the works, had not been re-ground for nine months, having simply been rubbed up on its cutting edge occasionally with an oilstone. The shavings taken by these cutters though broad were exceedingly thin; the cutters were probably not cutting one-twentieth of the time of 
the ronghing-out cutters, but in any case their endurance was extraordinary.

It had also been asked whether the rose-bit could be dispensed with. Though wonderfully good drilling could be done by good and correctly ground twist-drills, yet for exceedingly accurate holes, into which standard-size bolts or steady-pins had to drive tightly, or for holes in joints, links \&c., in which pins had to work with perfect template fit, he himself used an adjustable rymer having three blades, which were capable of the finest adjustment in case of wear, in order to maintain the standard sizes.

Hard gun-metal he found might be quite as easily milled as cast iron; and the yellow brass and softer gun-metals could be even more easily operated upon, provided the milling cutters were coarse in pitch, so that there was ample room between the teeth to receive the cuttings. The milling cutters were particularly suited for finishing soft brass, and could be worked with double the feed used for iron: producing brass mouldings or other complicated forms with great accuracy, and with a very highly finished surface. Such mouldings had been milled at the rate of $2 \frac{1}{2}$ inches in length per minute.

As to cast steel for cutting, he simply used the best qualities which were found to be the most suitable for each purpose, using one make for twist-drills, another for milling cutters, and so on. He had made numerous experiments on different kinds of cast toolsteel ; testing a tool made of any quality of steel which he had not previously used, against a tool made of steel which had hitherto given the best results. The trials were usually made in a planing machine having two tool-boxes on its cross-slide. One tool was fixed in the first box, and the other in the second one; and both were started to cut on the same casting (usually a lathe bed or planing-machine bed or table), cutting of course at the same speed, and with the same feed and depth of cut applied, so that the trial might be a perfectly fair one. But there was an extraordinary difference between steels. Some very hard steels, which would resist the file, seemed in cutting to perish away at the point. Steel which was hardened by simply heating and laying it down seemed, as far as he had tried it, to cut very satisfactorily, and to stand well; but there seemed to be one 
peculiarity about it: the quality of the tool, as it was ground away, became softer than it was at first. That difficulty was obviated by taking it to the smith, and re-hardening it. As to cast-iron, he had had much the same experience as the President. One of the greatest difficulties with a chilled-iron tool was, that if the point of the tool did give way, it was exceedingly difficult to re-grind it; and although it was excessively hard, it did not seem to have great endurance. He had not yet however tried the effect of cutting chilled metal with a chilled cast-iron tool.

Mr. Fielding had asked the maximum speed of cutting. That was alluded to in the paper, p. 248. The maximum speed for cutting wrought iron with a single tool was about $40 \mathrm{ft}$. per min. In his small lathes, it was quite common to cut at the rate of $30 \mathrm{ft}$. per min. Of course the speed had to vary, as remarked in the paper, with the depth of eut and the quality of the metal. Mr. Reynolds, had he been present, could he believed have told them that he had taken off with one tool, running at a slow speed, half a ton of steel shavings per day.

He had been invited to go into a description of the machines used in connection with the tools; but to introduce any such matter would have made the paper far too long, though he might perhaps do so on a future occasion. Mr. Robinson had called his attention to the milling machines made long ago at the Atlas Works, which no doubt would still do good work if proper cutters were supplied to them. One practical diffenlty, as Mr. Robinson had said, was in maintaining the cutters, before the emery-wheel and the mechanical system of grinding were adopted. The difficulty and expense of the old method were described in the paper, p. 244. Not only the making and finishing of the milling cutter, but also the maintaining of it in its proper state of efficiency, were exceedingly inexpensive. For instance a cutter would probably last a day without being re-ground; and to ro-grind it occupied four minutes oxly. The cutter was simply placed in the grinding machine on a mandril, adjusting it by worm and worm-wheel till the teeth to be ground were parallel to the lower slides. The cutter was thon passed rapidly, once forward and back, for the grinding of each tooth. The actual grinding of the whole cutter would not occupy more than $2 \frac{1}{2}$ to 3 minutes. 
Replying to Mr. Robinson, the tools shown in Figs. 8 and 10, Plate 19, were the only two special forms out of the whole of the cutters shown, and only one of these required any forging. They were tools which were rarely used. All parts of the swivel tool-holders being made of tongh forged steel, and the cutter being gripped with great rigidity by a powerful screw and nut, the whole was wonderfully free from jar.

Regarding the organisation of the best systems in workshops, his experience was that when this tool-holder system was once introduced the work went on with less supervision and anxiety to the overlookers, cost much less, and maintained a much higher standard of excellence.

Mr. Paget had mentioned the introduction of water through the tool to cool it. He had made a number of experiments for Col. Clay on that principle, and managed to cut at $40 \mathrm{ft}$. per min.: but at the end of the day from one difficulty and another he found it had not finished more work than an ordinary tool, and consequently it was abandoned.

Mr. Hulse had alluded to the practice at Sir Joseph Whitworth's with regard to tool-holders, as to which it was not needful to go into details; and also to the tool-holders not being able to take heavy cuts. If for tools doing exceedingly heavy work, and taking such cuts as Mr. Hulse spoke of, any advantage was found in using the slide-rest, by all means let it be used. What he said of the tool-holder system was, that for 100 machines out of 101 it was applicable; and not only applicable, but it was cheaper and produced better work. Mr. Hulse also alluded to a single-pointed tool doing more accurate work than a number of cutting teeth; but surely it stood to reason that a single point could not last as long as a number of teeth, and maintain the same accuracy.

Mr. Kitson had alluded to the milling cutter with a spiral groove in it, cutting a portion of the teeth away. His own experience was that when you began to cut a portion of the teeth away, you were obliged to reduce the speed, or else sacrifice the quality of the work. Many trials had been made at the Gresley Works from time to time with $\frac{1}{2}$-inch drills of ordinary form manufactured by himself, or by different engineers who had wished to see the effect of working a 
common against a twist-drill. The result had been that if a feed were put on the common drill, approaching that used for the same size of twist-drill, the former was invariably fractured, while on the contrary the twist-drill escaped fracture in a marvellous manner. The feed used was often so heary that the spindle of the drilling machine could be seen by the eye visibly descending. The drilling machines originally constructed by himself were provided with self-acting feeds, as coarse as could safely be applied for feeding forward the common drill. Since the twist-drill had been found to accomplish so much more work in a given time, he had increased all the feeds in his new drilling machines by about 90 per cent.

The President had described the work done by a flat drill, which drill was apparently machined all over and finished with great care, thus costing probably quite as much as a twist-drill could be purchased for. By that means no doubt all parts of the drill were made true and concentric with each other; and it would therefore be practicable to grind the cutting lips by machine so accurately, and to flute the cutting angles of the lips in such a manner, as to produce excellent cutting results for the short space of time the two flates would keep in order. But he imagined that when the drill was worn, say $\frac{1}{8}$ inch shorter, the proper angles for cutting would be found no longer existing; and to restore them, $\frac{1}{4}$ inch of the length of the drill would have to be ground to waste, before two new flutes could be again ground into the lips, so as to restore the proper cutting angles. Or, worse still, in a work where the flutes could not be mechanically ground in, the drill would have to be heated to soften it. Immediately this was resorted to, the finished accuracy of the drill was more or less destroyed; whereas in a good twist-drill, used with care and re-ground mechanically, the cutting angles remained the same, however short the drill might be ground. This, coupled with the fact that the wear took place only at the end of the drill and that the drill was hardened its whole length, produced the result that no softening had ever to be resorted to; the grinding or shortening of the drill was excessively slow; and, there being no waste or expense in repairs, the cost of the twist-drill, spread over its life-time, was exceedingly small. 
In Lancashire, on an approximate calculation based upon the employment of one hundred workmen, thirty of whom were turners and machine-men, the saving in wages where the tool-holder system was exclusively used, as compared with the old system of forged tools where each man re-ground them for himself, was $£ 80$ s. $10 d$. per week. This did not include the advantage of producing a greatly increased quantity of work per day from each machine, nor any of the advantages derived from the twist-drill system. 

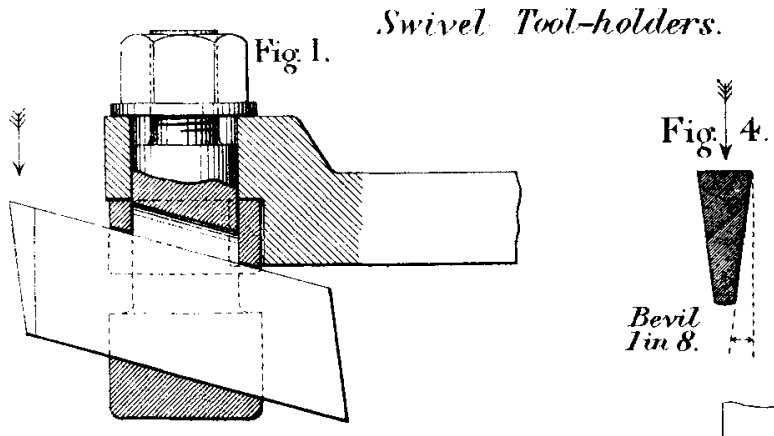

Fig. 3.
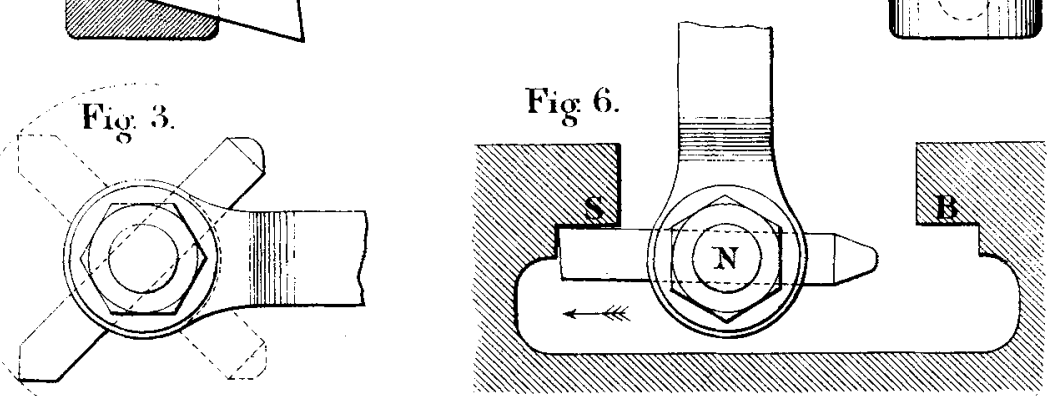

lige: 5

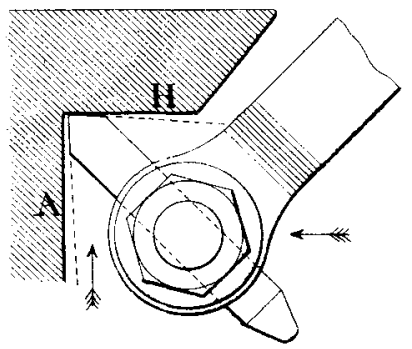

Fig. 8 .

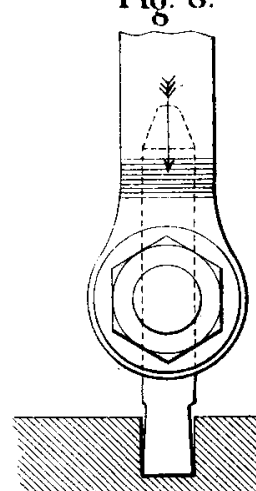

Fig. 2.

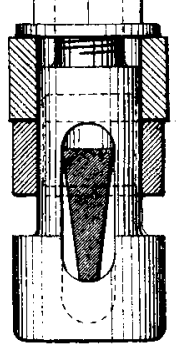

Fig: 10.

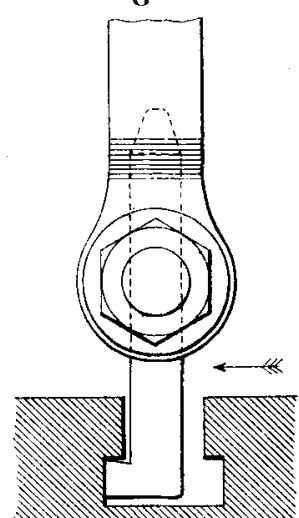

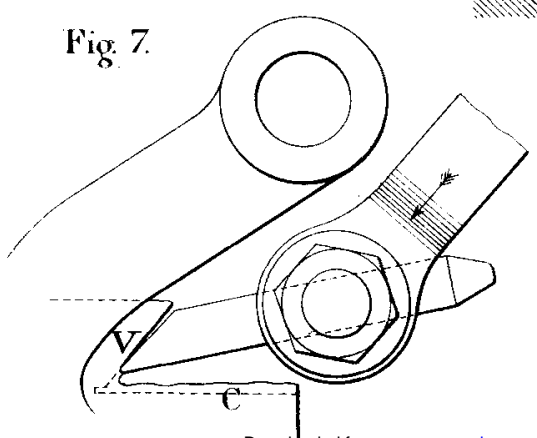

Downldaded from pme.sagepub.com at UNI July 3,2016 


\section{CUTTING OF METALS.}

Tool-holder for Planing Machines.

Fig. $9 \mathrm{~A}$.

Scrule 1 to 8 .
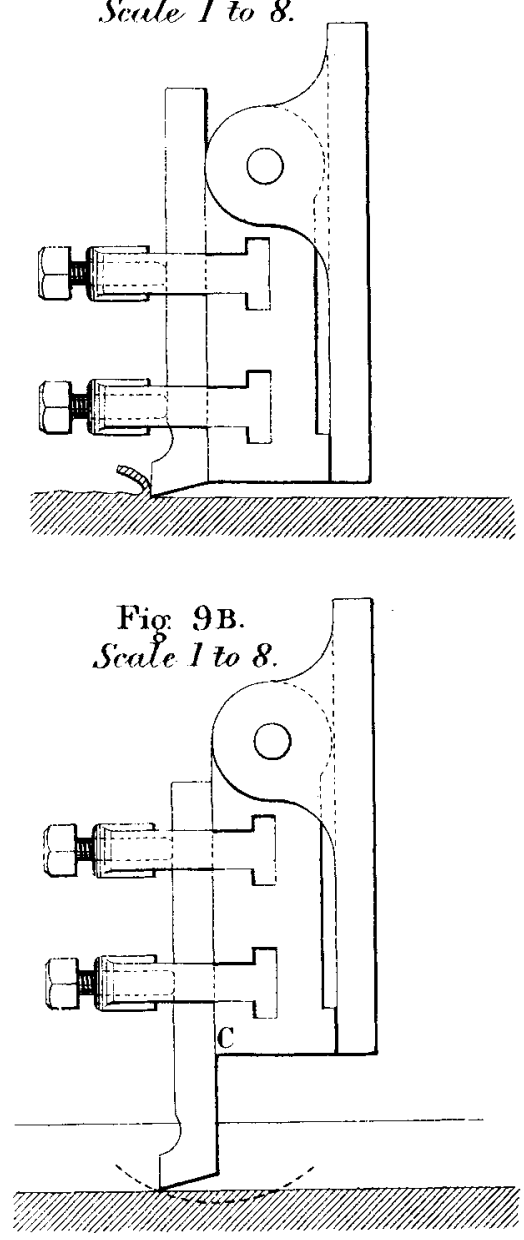

Fig: 9.

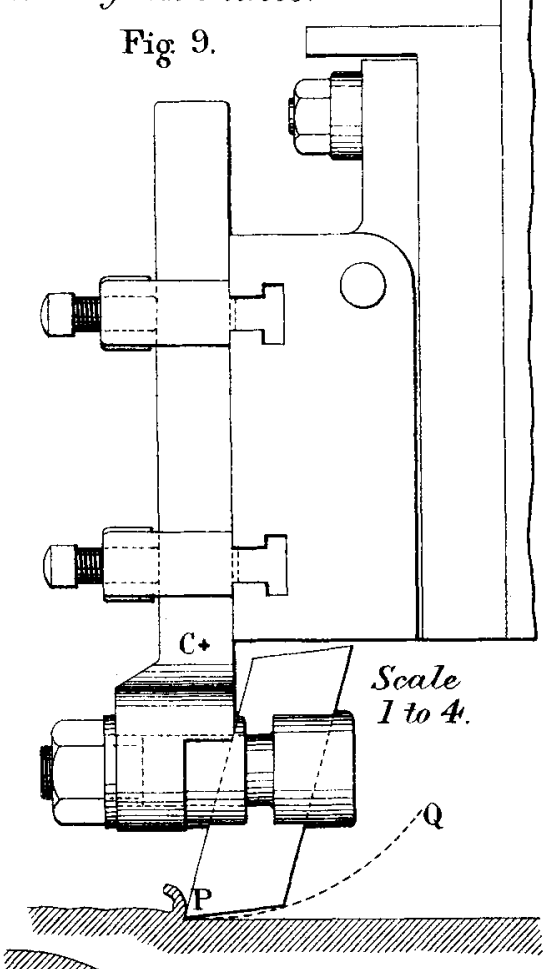

Fig: 12 A.

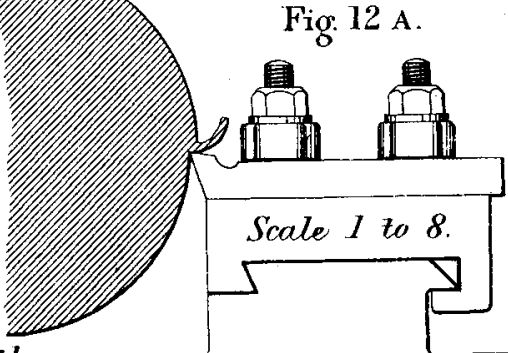

Tool-holder fir Screw-rutting Lathes.

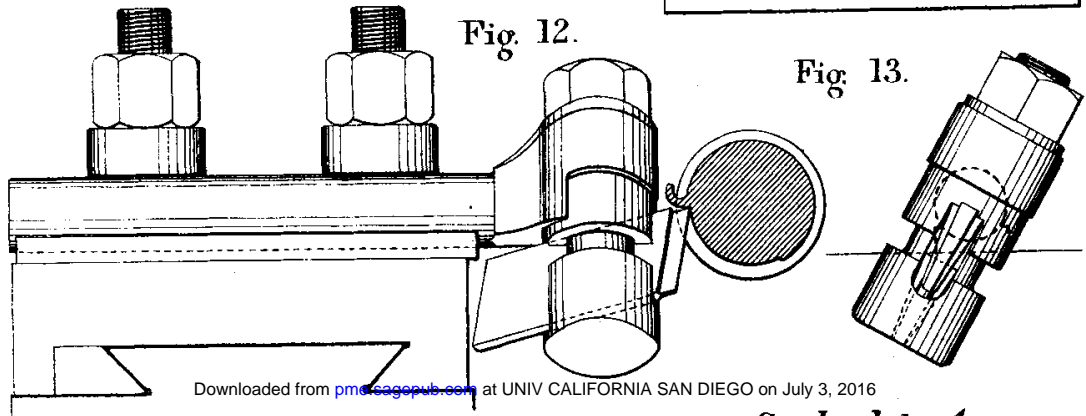




\section{Ending Tool-holder.}

Fig: 15. Fig: 14.

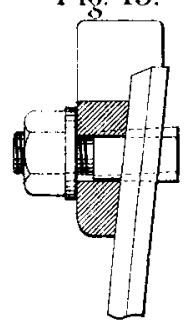

Srale 1 to 4



Fig. 17.

Sectiors of Ending Gutters.

Scale 1 to 2 .

Fig: 19

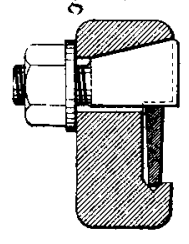

Parting Tool-holder.
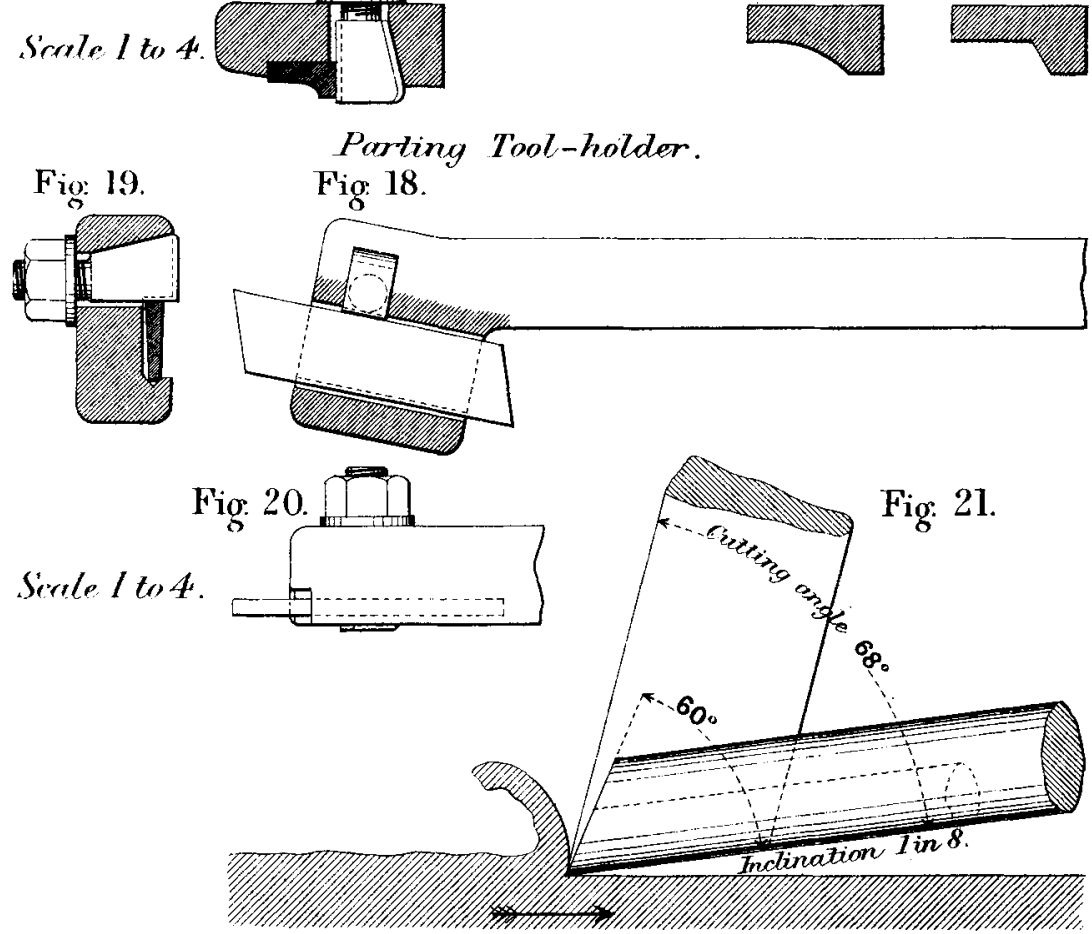

Fing 22. Angle Gouge

for . Swivel Cutters.

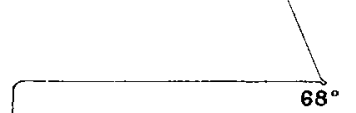

SWIVEL TOOLS

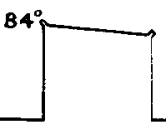

$>{ }^{84^{\circ}}$

Downloaded from pme sagepub.tom at UNIY CALIFORNIA \$AN DIEGO on July 3, 2016

(Proceedineas hiest. M. E. 1883.)
Fig. 23. Angle Gauge for Round Guzters.

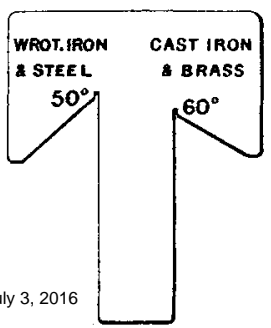






Fig. 29.

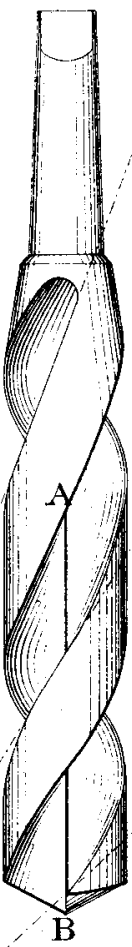

Fig. 26
CUTTING OF METALS. Drills.

Fig. 25.
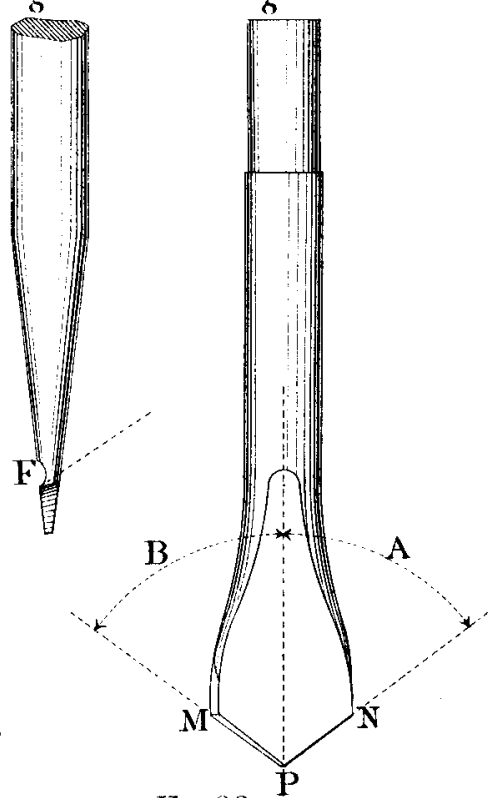

Fio: 28.

Fig. 27.

Plaze 22.

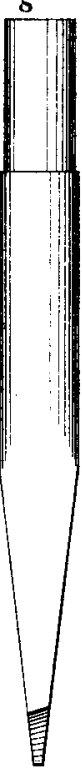

Fig. $27 \mathrm{~A}$.

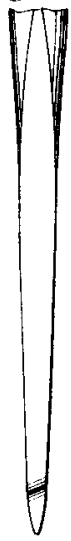

Fig. 28A.

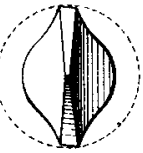

Fig. 30 . 


\section{CUTTING OF METALS. Plate 23.}

Milling Culters.

Fio: 33.

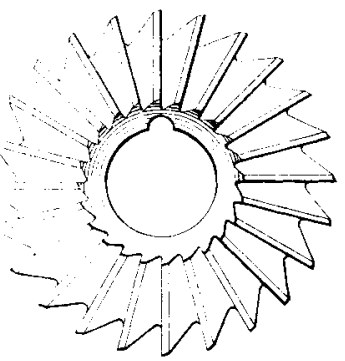

Fig: 40.

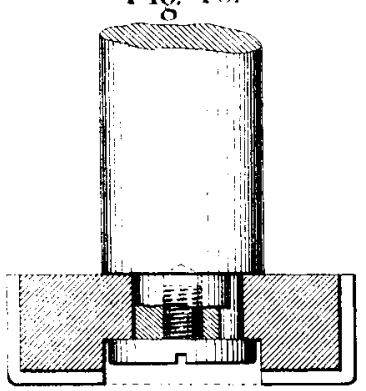

Fig. 41 .

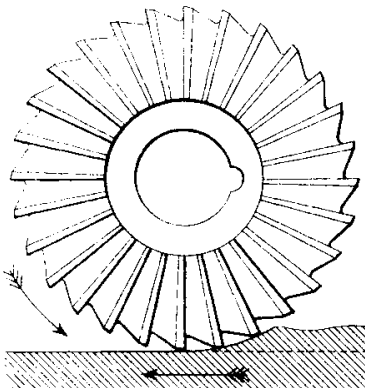

Fion: 42.

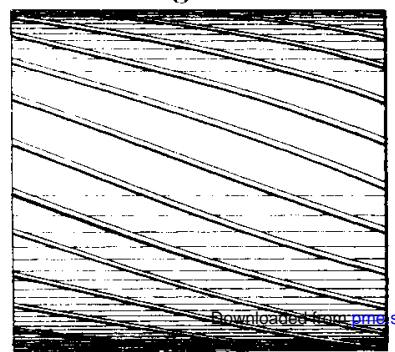

Fig: 34. Fig. $35 . \quad$ Fig. $36 . \quad$ Fig. 38.
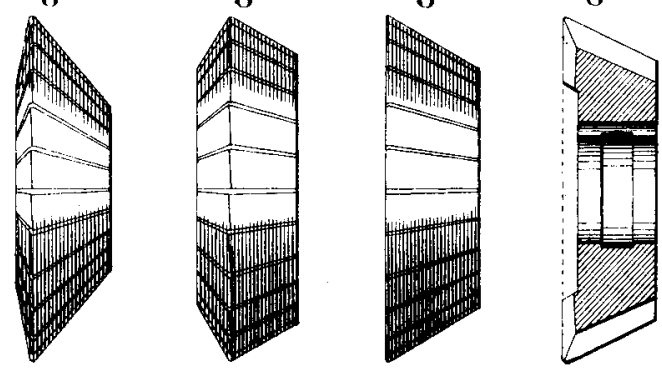

Fig. 39.

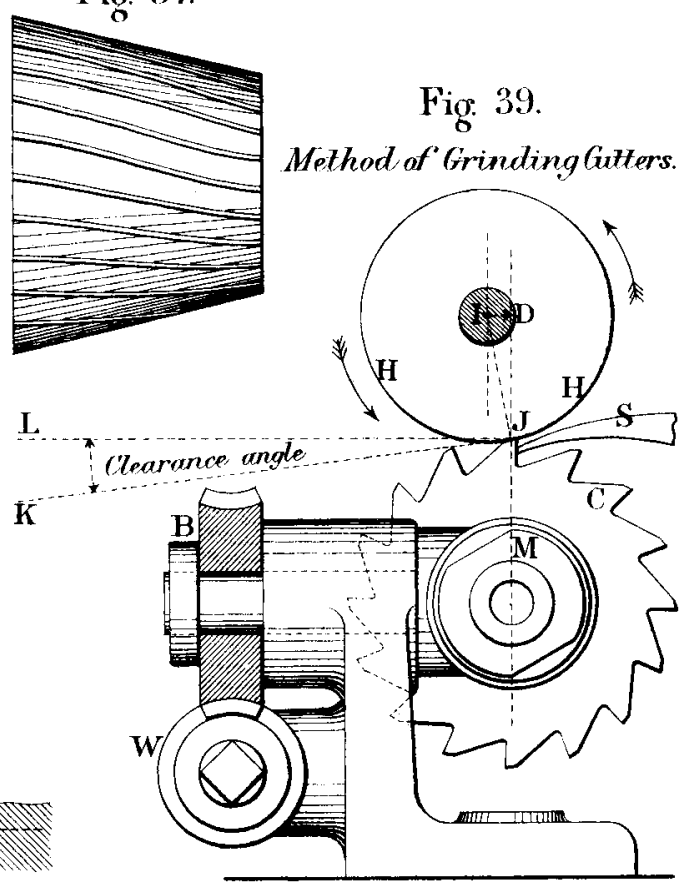

Fig. 43.

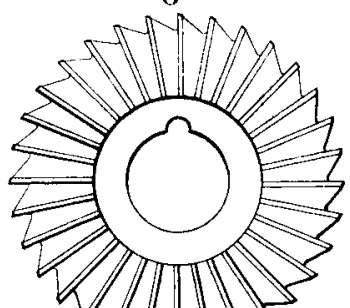

Fig. 44. Fig 45.
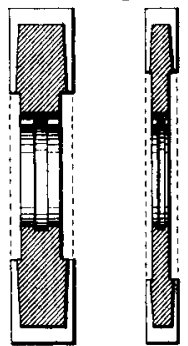
Fig. 47. French

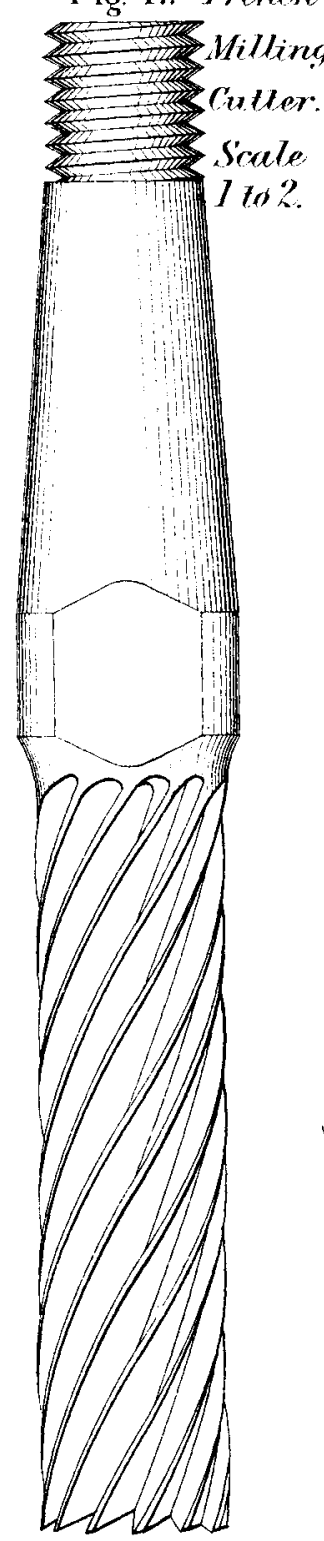

Fig: 48.

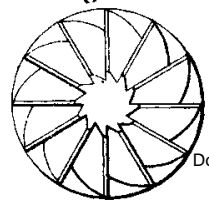

(B.onendings Inst M.E. 1883.)
Tool-holders with stight overhang. Fig. 50. Elevation.

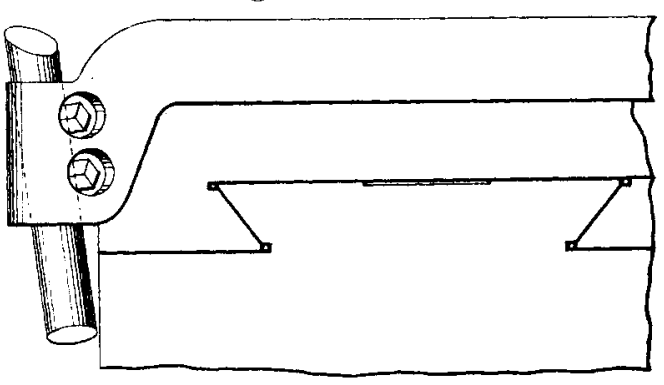

Fig: 51. Plan.
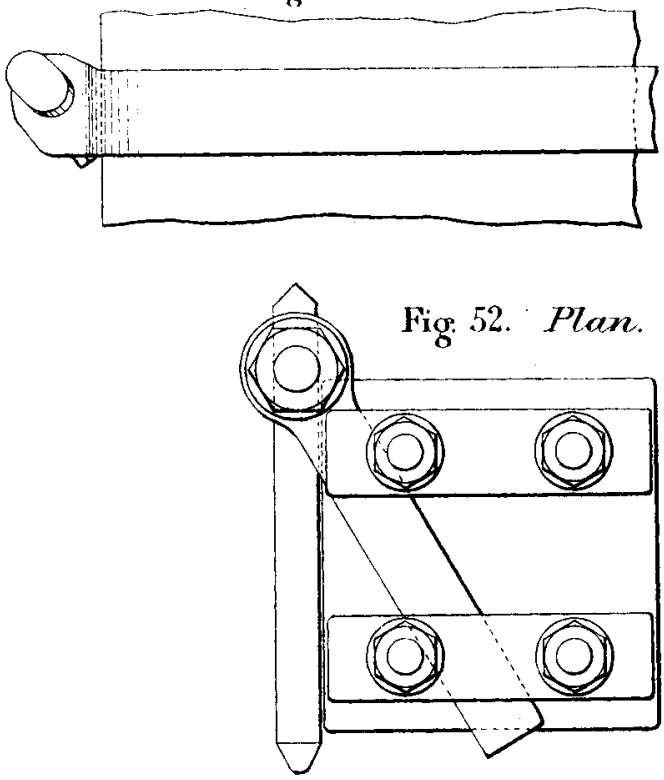

Fig.46. Grooved Fig: 49.

Section of Flute, French Gutter. Full size.
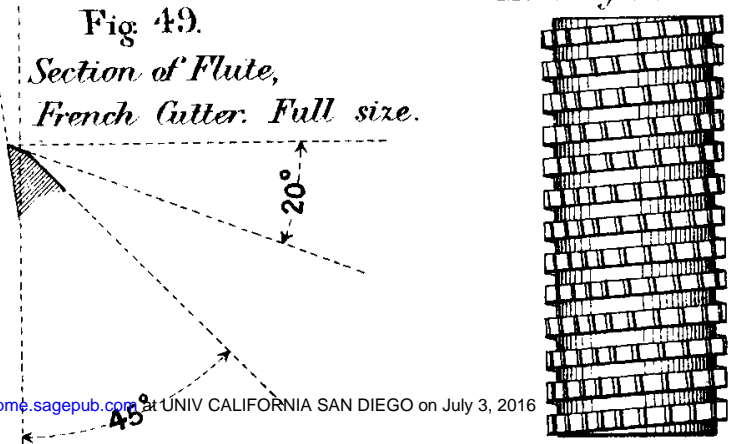